\title{
Inorganic lanthanide nanoprobes for background-free luminescent bioassays
}

\author{
Ping Huang ${ }^{1}$, Datao $\mathrm{Tu}^{1}$, Wei Zheng ${ }^{1}$, Shanyong Zhou ${ }^{1,2}$, Zhuo Chen ${ }^{2}$ and Xueyuan Chen ${ }^{1,2^{*}}$
}

\begin{abstract}
Luminescent bioassay techniques have been widely adopted in a variety of research and medical institutions. However, conventional luminescent bioassays utilizing traditional bioprobes like organic dyes and quantum dots often suffer from the interference of background noise from scattered lights and autofluorescence from biological matrices. To eliminate this disadvantage, the use of inorganic lanthanide $\left(\operatorname{Ln}^{3+}\right)$-doped nanoparticles (NPs) is an excellent option in view of their superior optical properties, such as the long-lived downshifting luminescence, near-infrared triggered anti-Stokes upconverting luminescence and excitation-free persistent luminescence. In this review, we summarize the latest advances in the development of inorganic $\mathrm{Ln}^{3+}$-doped NPs as sensitive luminescent bioprobes from their fundamental physicochemical properties to biodetection, including the chemical synthesis, surface functionalization, optical properties and their promising applications for background-free luminescent bioassays. Future efforts and prospects towards this rapidly growing field are also proposed.
\end{abstract}

\section{INTRODUCTION}

Sensitive and specific bioassay of trace amount of target analytes is essential for a variety of biomedical applications ranging from pharmaceutical preparation to disease diagnosis and therapy [1-3]. Among various bioassay methods, luminescent bioassay has received particular attention because of its high sensitivity and good specificity $[4,5]$. Conventional luminescent bioassay techniques such as enzyme-linked immunosorbent assay (ELISA), time-resolved (TR) fluoroimmunoassay (TRFIA), Förster resonance energy transfer (FRET) and TR-FRET assays have laid the foundation for many modern clinical applications [6-11]. However, these bioassays are impeded by the availability of traditional bioprobes like organic dyes, lanthanide $\left(\mathrm{Ln}^{3+}\right)$ chelates and quantum dots (QDs). The use of these bioprobes has a number of limitations. Organic dyes commonly possess poor photochemical stability and suffer from serious photobleaching [12]. The applicability of QDs is compromised by photoblinking and high toxic- ity of heavy metal elements like cadmium and selenium, especially for in vivo biosensing $[13,14]$. Moreover, both organic dyes and QDs may induce high background noise and considerable photodamage to the biological samples under ultraviolet (UV) excitation, which deteriorates their detection sensitivity for bioassays $[15,16]$. Although such background noise can be suppressed by the technique of TR photoluminescence (PL) through the use of the longlived luminescence of $\mathrm{Ln}^{3+}$-chelates, the poor photochemical stability, long-term toxicity and high cost of $\mathrm{Ln}^{3+}$-chelates remain a major issue [17]. These concerns fuel a crucial demand for the development of a new generation of luminescent bioprobes to circumvent the limitations of traditional ones.

Recently, with the explosion of nanoscience and nanotechnology, there is a growing dedication towards the development of diverse luminescent nanoprobes for biodetection and bioimaging. Representative of these nanoprobes includes $\mathrm{Au}$ nanoparticles (NPs) $[18,19]$, carbon nanomaterials (e.g., carbon dots and graphenes) [20-22], polymer NPs [23], silicon NPs [24] and inorganic $\mathrm{Ln}^{3+}$ doped NPs [16,25], etc. Among these nanomaterials, $\mathrm{Ln}^{3+}$ doped NPs are most intriguing due to their superior physicochemical properties, such as long-lived luminescence (from several to tens of milliseconds), large antenna-generated Stokes or anti-Stokes shifts, narrow emission bands, high resistance to photobleaching and photobleaking, and low toxicity $[23,24]$. Therefore, they are emerging as promising next-generation luminescent nano-bioprobes for versatile biomedical applications. Particularly, the long-lived downshifting luminescence (DSL) and high photochemical stability of $\mathrm{Ln}^{3+}$-doped NPs make them ideal alternative to $\mathrm{Ln}^{3+}$-chelates for TRPL biodetection to eliminate the short-lived background noise from scattered lights and autofluorescence from the biological samples [26,27]. Such unwanted background noise can also be overcome by using the unique anti-Stokes upconverting luminescence (UCL) and persistent luminescence of $\mathrm{Ln}^{3+}$-doped NPs. The large

\footnotetext{
${ }^{1}$ Key Laboratory of Optoelectronic Materials Chemistry and Physics, Fujian Institute of Research on the Structure of Matter, Chinese Academy of Sciences, Fuzhou 350002, China.

${ }^{2}$ State Key Laboratory of Structural Chemistry, and Danish-Chinese Centre for Proteases and Cancer, Fujian Institute of Research on the Structure of Matter, Chinese Academy of Sciences, Fuzhou 350002, China

"Corresponding author (email: xchen@fjirsm.ac.cn)
} 
anti-Stokes shift of UCL under near-infrared (NIR) excitation produces a neat emission spectrum without any interference of the excitation lights and biological autofluorescence $[28,29]$. The long-lasting phosphorescence (LLP) nature of persistent luminescent NPs (PLNPs) allows optical excitation before signal collection, thus providing an effective strategy to thoroughly suppress the background noise originating from in situ excitation [30-32]. These features promise $\mathrm{Ln}^{3+}$-doped NPs as sensitive nanoprobes for background-free luminescent bioassays.

This review summarizes the most recent advances in the development of inorganic lanthanide nano-bioprobes and their salient applications for background-free luminescent bioassays. To begin with, we present a brief overview of the chemical synthesis and surface functionalization of the nanoprobes. Next, we highlight the novel optical properties of $\mathrm{Ln}^{3+}$-doped NPs including DSL, UCL and LLP. Then, we exemplify several key applications of these nano-bioprobes for sensitive in vitro luminescent bioassays, with an emphasis on the background-free TRPL, UCL and LLP assays (Fig. 1). Finally, some important emerging trends and future efforts towards this active field are envisioned.

\section{CHEMICAL SYNTHESIS AND SURFACE FUNCTIONALIZATION}

For biomedical applications, there are some rigorous requirements for the bioprobes, such as bright luminescence, small size, biocompatibility and biosafety [33-36]. To meet these requirements, many efforts have been dedicated to the chemical synthesis and surface functionalization of inorganic $\mathrm{Ln}^{3+}$-doped NPs. In this section, we provide a brief overview of the general routes to the fabrication of inorganic lanthanide luminescent nanoprobes especially for bioassay applications, including controlled synthesis, surface modification and bioconjugation.

\section{Controlled synthesis}

In the past decade, a variety of approaches have been developed for the synthesis of high-quality $\mathrm{Ln}^{3+}$-doped luminescent NPs with controlled crystalline phases, morphologies,

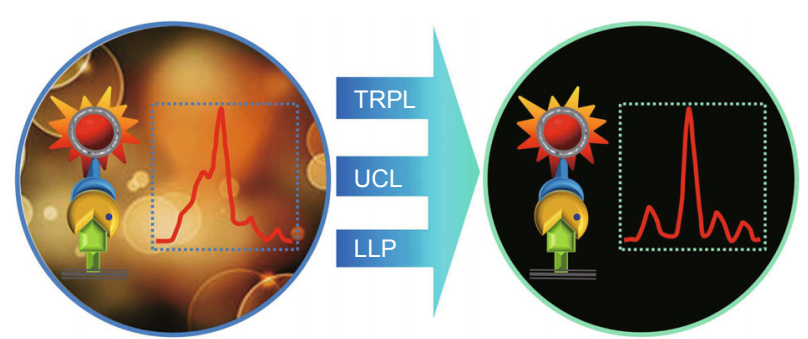

Figure 1 Schematic illustration of inorganic lanthanide nanoprobes for background-free luminescent bioassays based on their TRPL, UCL and LLP. sizes and desirable optical properties [37-42]. Among the established approaches, thermal decomposition [43-46], high-temperature coprecipitation [47-49] and hydro (solvo) thermal methods [50-52] are the most popular synthetic routes. These methods commonly make use of the organic surfactants to control the nucleation and growth of the nanocrystals. The available surfactants are either hydrophilic or lipophilic. The use of hydrophilic surfactants such as ethylenediaminetetraacetic acid (EDTA) [53], polyethylenimine (PEI) [54], polyethylene glycol (PEG) [55], polyacrylic acid (PAA) [56] and 2-aminoethyl dihydrogen phosphate (AEP) [27] allows for one-step synthesis of hydrophilic and biocompatible NPs, but the poor uniformity and monodispersity and the low PL efficiency of the resulting NPs restrict their widespread applications $[16,57]$. Instead, the lipophilic ligands such as oleic acid (OA), oleylamine (OM) and tri- $n$-octylphosphine oxide (TOPO) combined with other high boiling organic solvents like 1-octadecene (ODE) and trioctylamine (TOA) provide a mild solution for the synthesis of high-quality NPs with a narrow size distribution, good crystallinity and excellent optical properties, and thus are most frequently used in the synthesis of $\mathrm{Ln}^{3+}$-doped NPs $[43,47,50]$. For instance, through the thermal decomposition and high-temperature coprecipitation methods in the presence of OA, OM and ODE, we have fabricated a series of monodisperse $\mathrm{Ln}^{3+}$ doped fluoride NPs with intense DSL and/or UCL, such as $\mathrm{NaYF}_{4}$ [58], $\mathrm{NaGdF}_{4}$ [59], $\mathrm{NaScF}_{4}$ [60], $\mathrm{LiYF}_{4}$ [61], $\mathrm{LiLuF}_{4}$ [62], $\mathrm{KYF}_{4}$ [63], $\mathrm{KLaF}_{4}$ [64], $\mathrm{CaF}_{2}$ [65], $\mathrm{BaF}_{2}$ [65], $\mathrm{SrF}_{2}$ [65], and $\mathrm{Sr}_{2} \mathrm{YF}_{7}[66]$, etc.

On the nanoscale, surface quenching effect is the primary influential factor that deteriorates the PL efficiency of $\mathrm{Ln}^{3+}$-doped NPs, especially their UCL [67]. To surmount this disadvantage, surface passivation through core-shell architectures is a good choice. Also, the core-shell nanostructure design may endow the NPs with novel optical properties or integration of other functional modalities for diverse bioapplications [68-70]. For instance, through seed-mediated epitaxial layer-by-layer (LBL) growth, we have synthesized $\mathrm{CaF}_{2}: \mathrm{Ln}^{3+} @ \mathrm{CaF}_{2} \mathrm{NPs}$ with multi-shells and ultrasmall particle sizes ranging from $\sim 4 \mathrm{~nm}$ to $\sim 10$ $\mathrm{nm}$ (Figs 2a-e) [65]. It was found that the overall UCL intensity of $\mathrm{Er}^{3+}$ and $\mathrm{Tm}^{3+}$ in 3-monolayer (ML) core-shell NPs was enhanced by factors of $\sim 92$ and $\sim 1,700$, respectively, relative to their core-only counterparts. However, such seed-mediated heat-up synthesis is still laborious and time-consuming due to the tedious multi-cycle batch operations. Recently, more convenient approaches such as self-focusing by Ostwald ripening and one-pot successive LBL (SLBL) strategy through the alternate injection of different shell precursors have been developed to synthesize $\mathrm{Ln}^{3+}$-doped core-shell NPs [71-73]. Inspired by the 



Figure 2 (a) Seed-mediated heat-up synthesis of $\mathrm{CaF}_{2}: \mathrm{Ln}^{3+} @ \mathrm{CaF}_{2}$ core-shell NPs via a high-temperature co-precipitation route. TEM images of $\mathrm{CaF}_{2}: \mathrm{Yb}, \mathrm{Er}$ (b) core-only, (c) 1-ML, (d) 2-ML, and (e) 3-ML core-shell NPs. (a-e, Adapted with permission from Ref. [65]. Copyright 2013, WileyVCH Verlag GmbH \& Co. KGaA). (f) SLBL method for the synthesis of $\mathrm{LiLuF}_{4}: \mathrm{Ln}^{3+}$ core-shell UCNPs via thermal decomposition. TEM images of LiLuF $_{4}: \mathrm{Yb}, \mathrm{Er}$ (g) core-only and core-shell UCNPs with (h) 8 MLs and (i) 16 MLs. (f-i, Adapted with permission from Ref. [62]. Copyright 2014, Wiley-VCH Verlag GmbH \& Co. KGaA).

SLBL method, we further designed a unique strategy for the synthesis of multi-shell $\mathrm{LiLuF}_{4}: \mathrm{Ln}^{3+} @ \mathrm{LiLuF}_{4}$ upconversion (UC) NPs via thermal decomposition (Figs 2f-i) [62]. It was observed that the overall UCL intensity was remarkably enhanced upon successive shell passivation. The absolute UC quantum yields (QYs) of $\mathrm{Er}^{3+}$ and $\mathrm{Tm}^{3+}$ were, respectively, improved from $0.11 \%$ and $0.61 \%$ in the core-only NPs to $5.0 \%$ and $7.6 \%$ in $16-\mathrm{ML}$ core-shell NPs, upon $980 \mathrm{~nm}$ laser excitation at a power density of 127 $\mathrm{W} \mathrm{cm}{ }^{-2}$. To the best of our knowledge, the UC QYs of 5.0\% and $7.6 \%$ for $\mathrm{Er}^{3+}$ and $\mathrm{Tm}^{3+}$ are the highest among those $\mathrm{Ln}^{3+}$-doped UCNPs ever reported, under NIR excitation at equivalent power density. Compared with the previous methods, our strategy is much easier to handle without the need for the precipitation of core NPs and the tedious multi-cycle operations or the alternate injection of different shell precursors, thus providing a more facile and general synthetic route for $\mathrm{Ln}^{3+}$-doped core-shell NPs.

\section{Surface modification}

The synthesized $\mathrm{Ln}^{3+}$-doped NPs aforementioned, in most cases, are hydrophobic and incompatible with biological systems due to the lipophilic ligands such as OA or OM capping on their surface. A general solution to this problem is the surface modification of the hydrophobic NPs with a hydrophilic ligand bearing appropriate functional groups [74]. For this purpose, a number of surface modification strategies such as ligand exchange [75-77], ligand oxida- 
tion [78,79], ligand-free synthesis [80], ligand attraction $[81,82]$, electrostatic layer-by-layer assembly $[83,84]$ and surface silanization $[85,86]$ have been established (Fig. 3 ).

Ligand exchange is one of the most general and efficient approaches to convert hydrophobic $\mathrm{Ln}^{3+}$-doped NPs into hydrophilic ones. In a typical ligand exchange procedure, organic molecules or polymers with hydrophilic moieties (e.g., PEI, PEG, PAA and AEP) are employed to exchange the lipophilic surfactants of the original NPs, which endow the NPs with high water solubility and additional functional groups (e.g., amino, carboxylic and thiol groups) for subsequent bioconjugation [75-77]. Ligand oxidation is primarily based on the oxidation of the unsaturated carbon-carbon double bonds of the capping ligands (e.g., $\mathrm{OA}$ ), and thus is only applicable to a limit number of organic surfactants [78,79]. The capping ligands anchored on the surface of the original NPs can be removed through a simple acid (or excess ethanol) treatment process to yield water-soluble and ligand-free NPs. The removal of the capping ligands makes the positively charged $\mathrm{Ln}^{3+}$ ions exposed on the surface of the ligand-free NPs, enabling the NPs for direct conjugation with electronegative groups of hydrophilic and biocompatible molecules for further bioapplications $[80,87,88]$. The approach of ligand attraction mainly takes advantage of hydrophobic-hydrophobic van der Waals interactions between selected amphiphilic polymers and original lipophilic ligands to realize phase transformation of the NPs. In a typical ligand attraction process, the hydrophobic portion of the amphiphilic polymers interacts with the organic layer of the NPs via hydrophobic attraction, while the hydrophilic portion facing outwards interacts with the aqueous solvent and renders the NPs water-soluble [81,82]. Besides the hydrophobic-hydrophobic interactions, the electrostatic attraction between oppositely charged organic species such as poly(allylamine

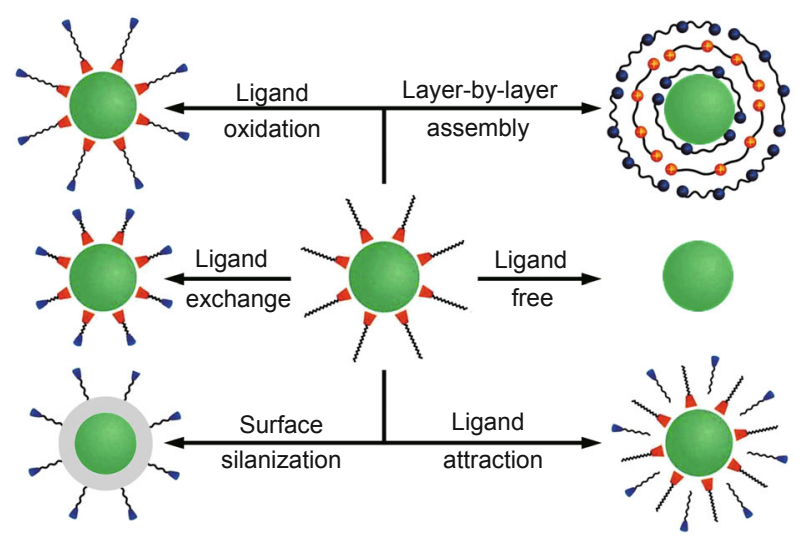

Figure 3 Typical surface modification strategies to render the hydrophobic $\mathrm{Ln}^{3+}$-doped NPs hydrophilic and simultaneously endow them with designed functional groups. Reprinted with permission from Ref. [87]. Copyright 2014, Royal Society of Chemistry.

hydrochloride) (PAH) and poly(styrene sulfonate) (PSS) can also be utilized to obtain hydrophilic NPs through LBL assembly around the hydrophobic NPs [83,84]. Surface silanization or silica coating commonly makes use of an inorganic amorphous silica shell to fabricate a hybrid core-shell nanocomposite. Such an amorphous silica shell is water-soluble, photostable and biocompatible, which allows easy surface carboxyl-functionalization (or amine-functionalization) for further bioconjugation $[85,86]$. Specifically, the mesoporous silica $\left(\mathrm{mSiO}_{2}\right)$ shell or yolk shell coating endows the NPs with excellent loading capabilities with diverse biological molecules or other functional moieties, making them ideal candidates for applications in multimodal bioimaging, targeted drug delivery and photodynamic therapy [89-92].

\section{Bioconjugation}

Bioconjugation of specific biomolecules to the surface of $\mathrm{Ln}^{3+}$-doped luminescent NPs is essential for their bioanalytical applications. The conjugation of biomolecules could impart the NPs with both biocompatibility and desired functionality such as the ability of specific recognition [87,93-95]. The available biomolecules cover from small biomolecules like biotin and folic acid to biomacromolecules like avidin, streptavidin, antibodies, peptides, aptamers and DNA, subjected to the expected target capabilities.

In general, the bioconjugation methods for $\mathrm{Ln}^{3+}$-doped NPs are based on either physical adsorption or chemical bonding or their combinations (Fig. 4) [96-99]. With known isoelectric points, the $\zeta$ potentials of the NPs and the conjugating biomolecules can be readily tuned in opposite charges by adjusting the $\mathrm{pH}$ value of the reaction buffers, which allows for direct bioconjugation of the NPs via electrostatic attraction [100]. For example, by utilizing the positively charged $\mathrm{Ln}^{3+}$ ions exposed on ligand-free $\mathrm{LiLuF}_{4}: \mathrm{Yb}$, Er UCNPs, we have succeeded in the avidin functionalization of the UCNPs through electrostatic interaction [62]. Likewise, Lu and coworkers [101] developed an exceptionally simple strategy for the direct synthesis of DNA-func-

a
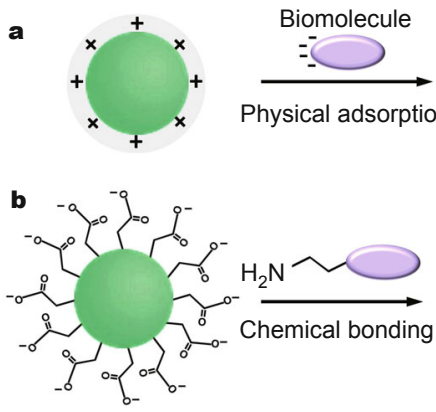

Figure 4 Schematic illustration of general bioconjugation methods through (a) physical adsorption and (b) chemical bonding. 
tionalized $\mathrm{NaYF}_{4}: \mathrm{Yb}$,Er UCNPs from as-prepared hydrophobic ones through electrostatic interaction between the negatively charged phosphates of the DNA and the naked $\mathrm{Ln}^{3+}$ ions on the surface of the NPs. However, such physical adsorption is not steady enough and usually yields unstable biofunctionalized NPs. By contrast, chemical bonding provides a robust and stable conjugation force, thus is more favorable for the bioconjugation of $\mathrm{Ln}^{3+}$-doped NPs. In most cases, the functional groups of the conjugating biomolecules can be activated to react with those of the NPs and form a tight covalent bond (e.g., amide bond). Functional groups like maleimide, thiol, carboxylic, aldehyde and amine are usually used for the attachment of biomolecules $[25,87]$. For example, by utilizing the free carboxylic groups on the surface of $\mathrm{NaYF}_{4}: \mathrm{Yb}$, Er UCNPs, Li and coworkers [83] demonstrated the conjugation of streptavidin to the surface of the NPs through a standard ethyl(dimethylaminopropyl) carbodiimide (EDC)/N-hydroxysuccinimide (NHS) bioconjugation protocol. Similarly, we conjugated amine-functionalized $\mathrm{ZrO}_{2}: \mathrm{Ln}^{3+}$ and $\mathrm{CaF}_{2}: \mathrm{Ln}^{3+}$ NPs with biotin and amino-terminal fragment (ATF) of urokinase plasminogen activator (uPA) in N,N-dimethylformamide (DMF) by using $o$-Benzotriazole- $N, N, N^{\prime}, N^{\prime}$-tetramethyluronium-hexafluoro-phosphate (HBTU) and $N, N$-diisopropylethy (DIEA) as cross-linking reagents $[65,102]$. Despite the validity of these methods, the functional groups are omnipresent in biological systems and cannot be labeled specifically in complex biological systems. In this sense, the so-called "click-chemistry" is an attractive alternative because the functional groups involved (e.g., azido and alkyne) are hardly present in biomolecules including proteins and oligomers and thus high selectivity and high yields of biomolecules conjugation can be guaranteed $[103,104]$. In addition, the strong coordination capability of the naked metal ions such as $\mathrm{Ln}^{3+}$ on the surface of ligand-free NPs can be exploited for direct bioconjugation. For example, we synthesized biotinylated $\mathrm{NaEuF}_{4}$ and $\mathrm{Sr}_{2} \mathrm{YF}_{7} \mathrm{NPs}$ based on the strong chelation of the exposed $\mathrm{Ln}^{3+}$ ions on the surface of their ligand-free counterparts, which can be steadily dispersed in varied buffer solutions for months without any observable aggregates $[66,105]$.

It is worthy of noting that the bioactivity of the conjugating biomolecules and the dispersability of the NPs should be guaranteed during bioconjugation. Furthermore, to avoid non-specific binding in subsequent bioanalytical applications, it is necessary to block the residual binding sites of the NPs after the conjugation. Bovine serum albumin (BSA) and human serum albumin (HSA) are frequently used for this purpose.

\section{OPTICAL PROPERTIES}

Trivalent lanthanide ions have abundant electronic energy levels in the $[\mathrm{Xe}] 4 \mathrm{f}^{N}(N=0-14)$ electronic configuration with unfilled $4 \mathrm{f}^{N}$ electron shell shielded by filled $5 \mathrm{~s}^{2} 5 \mathrm{p}^{6}$ subshells. This unique electronic structure enables $\mathrm{Ln}^{3+}$ as excellent luminescent centers in inorganic NPs to emit photons efficiently in a broad spectral region from UV to visible and NIR. Owing to the parity-forbidden nature of the intra- $4 \mathrm{f}^{N}$ transitions within $\mathrm{Ln}^{3+}$ and their peculiar electronic structures, $\mathrm{Ln}^{3+}$-doped NPs possess superior optical characteristics, such as sharp emission peaks, large antennagenerated Stokes or anti-Stokes shifts, long PL lifetimes and high photochemical stability, which make them extremely suitable for use as an alternative to traditional luminescent bioprobes for versatile biomedical applications. In this section, we highlight the distinct optical properties of $\mathrm{Ln}^{3+}$-doped luminescent NPs, including their long-lived DSL, NIR-triggered UCL and excitation-free LLP that are unique for background-free luminescent bioassays.

\section{Downshifting luminescence}

DSL refers to the phenomenon that one high-energy photon is transformed into one or more lower energy photons. Although DSL is expected for most $\mathrm{Ln}^{3+}$ ions in theory, intense and practically useful DSL in the visible region is generally produced by those $\mathrm{Ln}^{3+}$ ions with large energy gaps between the emitting energy levels and the next low-lying states, such as $\mathrm{Eu}^{3+}, \mathrm{Tb}^{3+}, \mathrm{Sm}^{3+}$, and $\mathrm{Dy}^{3+}$. Since the emissions via $4 \mathrm{f}-4 \mathrm{f}$ transitions are parity-forbidden, these DSL emitters usually have a long PL lifetime ( $\mu$ s-ms range). The long-lived DSL of $\mathrm{Ln}^{3+}$ can be easily distinguished from the short-lived background noise from biological substances by setting appropriate delay time and gate time, thus is favorable for background-free TRPL biodetection [17,106-110].

To achieve efficient DSL from $\mathrm{Ln}^{3+}$-doped NPs, it is essential to select desirable host materials and optimize the dopant concentrations. Ideal host materials should possess adequate transparency within the wavelength range of interest, low phonon energy, high chemical stability, closematched lattice and low local site symmetry for $\mathrm{Ln}^{3+}$ dopants [111-113]. In this sense, inorganic compounds (e.g., fluoride, oxide, phosphate, vanadate, borate, tungstate and molybdate) containing rare earth ions, alkaline earth ions, and a number of transition metal ions (e.g., $\mathrm{Zr}^{4+}, \mathrm{Ti}^{4+}$, and $\mathrm{Mn}^{2+}$ ) are suitable candidates for $\mathrm{Ln}^{3+}$ doping to generate efficient DSL. The dopant concentrations are usually kept low to avoid the concentration quenching of $\mathrm{Ln}^{3+}$ luminescence, especially for those $\mathrm{Ln}^{3+}$ ions with smaller energy gaps. For example, the optimized dopant concentrations in $\beta-\mathrm{NaYF}_{4} \mathrm{NPs}$ are normally below 10 at.\% for $\mathrm{Tb}^{3+}$ and $\mathrm{Eu}^{3+}$ and below 3 at.\% for $\mathrm{Sm}^{3+}$ and $\mathrm{Dy}^{3+}$ [114-116]. More importantly, as $\mathrm{Ln}^{3+}$ ions typically have a low extinction coefficient with a narrow bandwidth due to the parity-forbidden nature of intra- $4 \mathrm{f}^{N}$ transitions, it is highly demand- 
ed to introduce an antenna that can effectively harvest the incident light and sensitize the $\mathrm{Ln}^{3+}$ luminescence. Optical entities with large absorption cross-sections such as $\mathrm{Ce}^{3+}$, $\mathrm{Bi}^{3+},\left[\mathrm{VO}_{4}\right]^{3-}$, and $\mathrm{Ln}^{3+}-\mathrm{O}^{2-}$ charge transfer states as well as the host absorption from $\mathrm{Gd}^{3+}$ and exciton recombination from semiconductor NPs can be utilized to sensitize the DSL of $\mathrm{Ln}^{3+}[117,118]$. For instance, $\mathrm{Ce}^{3+}$ and $\mathrm{Bi}^{3+}$ are frequently co-doped with $\mathrm{Tb}^{3+}$ and $\mathrm{Eu}^{3+}$, respectively, in NPs to sensitize their luminescence $[119,120]$. Previously, we realized the incorporation of $\mathrm{Ln}^{3+}$ into the lattice of a series of semiconductor NPs (e.g., $\mathrm{ZnO}, \mathrm{TiO}_{2}, \mathrm{SnO}_{2}, \mathrm{ZrO}_{2}, \mathrm{Ga}_{2} \mathrm{O}_{3}$ and $\mathrm{In}_{2} \mathrm{O}_{3}$ ) where strong host-sensitizing $\mathrm{Ln}^{3+} \mathrm{PL}$ occurred [121-133]. Likewise, through the sensitization of $\mathrm{Gd}^{3+}$, we obtained intense red, green and blue emissions in $\mathrm{Eu}^{3+}$, $\mathrm{Tb}^{3+}$ and $\mathrm{Dy}^{3+}$ singly-doped $\mathrm{KGdF}_{4}$ NPs with their Stokes shifts larger than $250 \mathrm{~nm}$ and PL lifetimes of $\sim 10.3, \sim 9.5$, and $\sim 1.6 \mathrm{~ms}$, respectively (Figs $5 \mathrm{a}$ and b) [111]. Through the control of dopant concentrations and combinations, efficient multicolor emissions can also be tuned in $\mathrm{Eu}^{3+}, \mathrm{Dy}^{3+}$ and $\mathrm{Sm}^{3+}$ co-doped $\mathrm{YVO}_{4} \mathrm{NPs}$ through the sensitization of $\left[\mathrm{VO}_{4}\right]^{3-}$ upon UV excitation at $280 \mathrm{~nm}$ (Fig. 5c) [112].
Although the visible DSL of $\mathrm{Ln}^{3+}$-doped NPs is favorable for in vitro biodetection, it is not appropriate for in vivo bioapplications as the UV excitation light could damage biological specimens. Recently, with the rapid advances in deep-tissue bioimaging, there has reviving interest for NIR-to-NIR Ln $^{3+}$-doped DSL NPs, because of their high PL efficiency and the minimal response of the cells and tissues to NIR light [134-137]. The available NIR emitters include $\mathrm{Nd}^{3+}, \mathrm{Yb}^{3+}, \mathrm{Ho}^{3+}, \mathrm{Er}^{3+}$ and $\mathrm{Tm}^{3+}$, which are also key dopants in UCNPs for producing efficient anti-Stokes UCL, as will be overviewed in the following subsection.

\section{Upconverting luminescence}

UCL is a nonlinear optical process that converts two or more low-energy pump photons into a higher-energy output photon. Different from the UC processes via virtual energy states such as multiphoton absorption or second harmonic generation that require expensive ultra-short pulse lasers to perform the excitation, $\mathrm{Ln}^{3+}$-doped UCNPs generally take advantage of a more efficient energy transfer UC (ETU) process through the real intermediary levels of $\mathrm{Ln}^{3+}$,
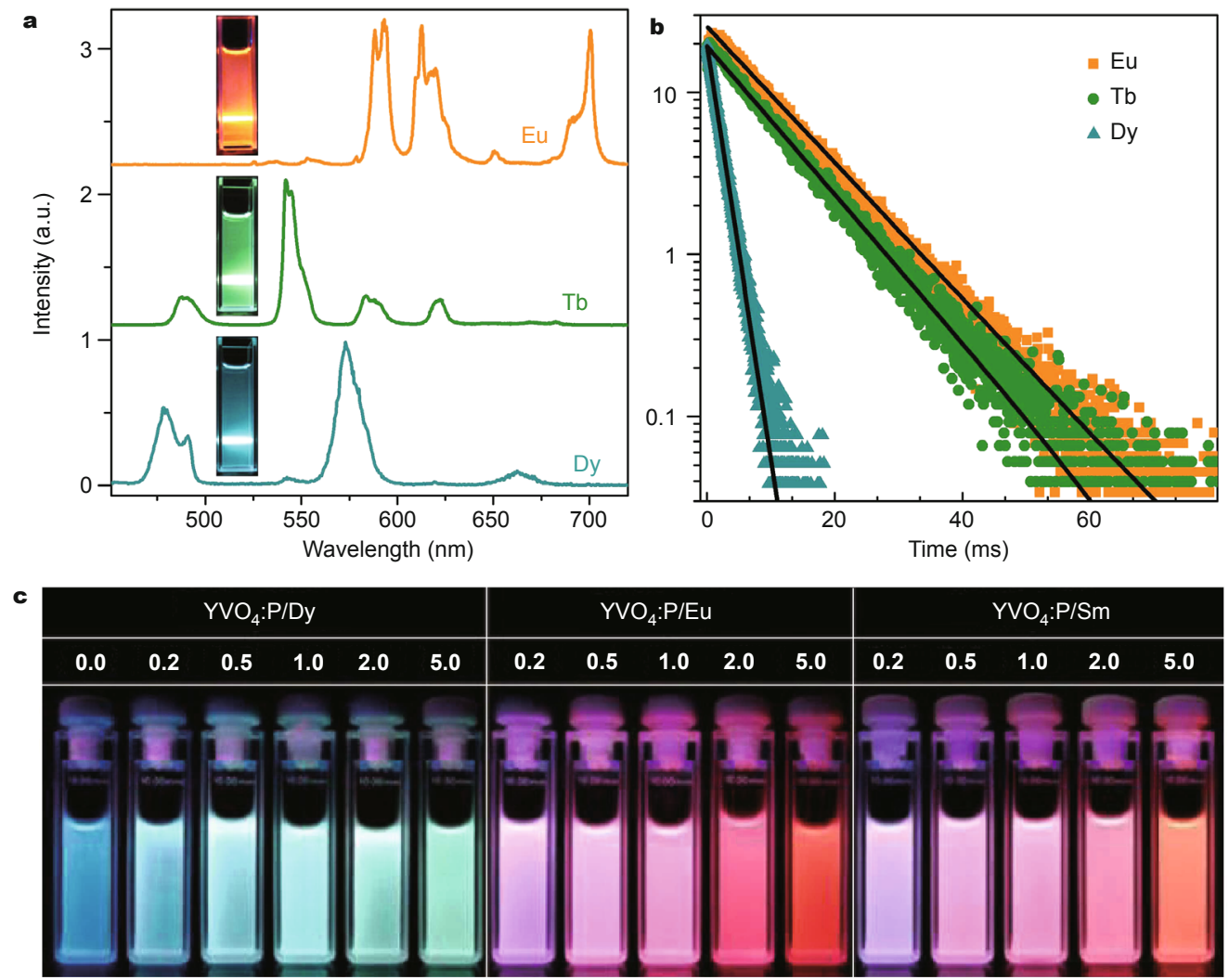

Figure 5 (a) Emission spectra and (b) PL decay curves of $\mathrm{Eu}^{3+}\left(5.0\right.$ at.\%), $\mathrm{Tb}^{3+}\left(5.0\right.$ at.\%), and $\mathrm{Dy}^{3+}\left(0.5\right.$ at. \%) singly-doped $\mathrm{KGdF}_{4} \mathrm{NPs}_{\text {in }}$ aqueous solutions (1.0 mM) upon $272 \mathrm{~nm}$ excitation. The insets show the PL photographs from the corresponding solutions (Adapted with permission from Ref. [111]. Copyright 2012, American Chemical Society). (c) Multicolor DSL tuning of (Ln,P)-doped $\mathrm{YVO}_{4}$ NPs by varying the concentrations of Dy ${ }^{3+}$, $\mathrm{Eu}^{3+}$, and $\mathrm{Sm}^{3+}$ ions (Adapted with permission from Ref. [112]. Copyright 2008, Wiley-VCH Verlag GmbH \& Co. KGaA). 
thus can be excited by using a low-cost continuous-wave NIR diode laser. Owing to the remarkable light penetration depth and the absence of autofluorescence in biological specimens under NIR excitation, $\mathrm{Ln}^{3+}$-doped UCNPs are ideal for use as alternatives to conventional DSL bioprobes for various biomedical applications $[29,138]$.

The commonly used UCL activators are those $\mathrm{Ln}^{3+}$ ions with metastable and long-lived intermediary energy levels acting as storage reservoirs for the pump energy, such as $\mathrm{Er}^{3+}, \mathrm{Tm}^{3+}$ and $\mathrm{Ho}^{3+}$ (Fig. 6a). To facilitate the ETU process and enhance the UCL efficiency, $\mathrm{Yb}^{3+}$ ions, with a larger NIR ( 980 nm) absorption cross-section, are often codoped as sensitizers. The sensitizer $\mathrm{Yb}^{3+}$ ions are usually heavily doped to maximize the absorption, while the doping concentrations of the activators are kept low to minimize the energy loss through cross relaxation. The typical dopant concentrations in $\beta-\mathrm{NaYF}_{4}$ UCNPs are 2 at.\%, 0.5 at.\% and 20 at.\% for $\mathrm{Er}^{3+}, \mathrm{Tm}^{3+}$ and $\mathrm{Yb}^{3+}$, respectively [139]. The selection criterion for the hosts of UCNPs is identical to that of their DSL counterparts. So far, the most efficient and widely used UCNPs is $\mathrm{Yb} / \mathrm{Er}$ or $\mathrm{Yb} / \mathrm{Tm}$ co-doped $\beta-\mathrm{NaYF}_{4}$, though some novel UC host materials such as $\beta-\mathrm{NaLuF}_{4}$ and tetragonal-phase $\mathrm{LiLuF}_{4}$ have been newly reported to have a higher UCL efficiency [62,140-143].

Recently, with the rapid development of $\mathrm{Ln}^{3+}$-doped UCNPs, many interesting UCL properties such as multicolor emission, single-band emission, broad-band emission, stimulated emission and lasing, and UCL lifetime multiplexing have been explored [144-153]. For instance, by the control of the doping concentrations of $\mathrm{Er}^{3+}, \mathrm{Tm}^{3+}$ and $\mathrm{Yb}^{3+}$, multicolor UCL was obtained in $\mathrm{NaYF}_{4}, \mathrm{NaGdF}_{4}$ and $\mathrm{YF}_{3} \mathrm{NPs}_{\mathrm{s}}$ up single-wavelength excitation at $980 \mathrm{~nm}$ (Fig. 6c) [154-158]. Based on energy transfers between $\mathrm{Mn}^{2+}$ and $\mathrm{Ln}^{3+}$ (e.g., $\mathrm{Er}^{3+}, \mathrm{Tm}^{3+}$ and $\mathrm{Ho}^{3+}$ ), single-band UCL
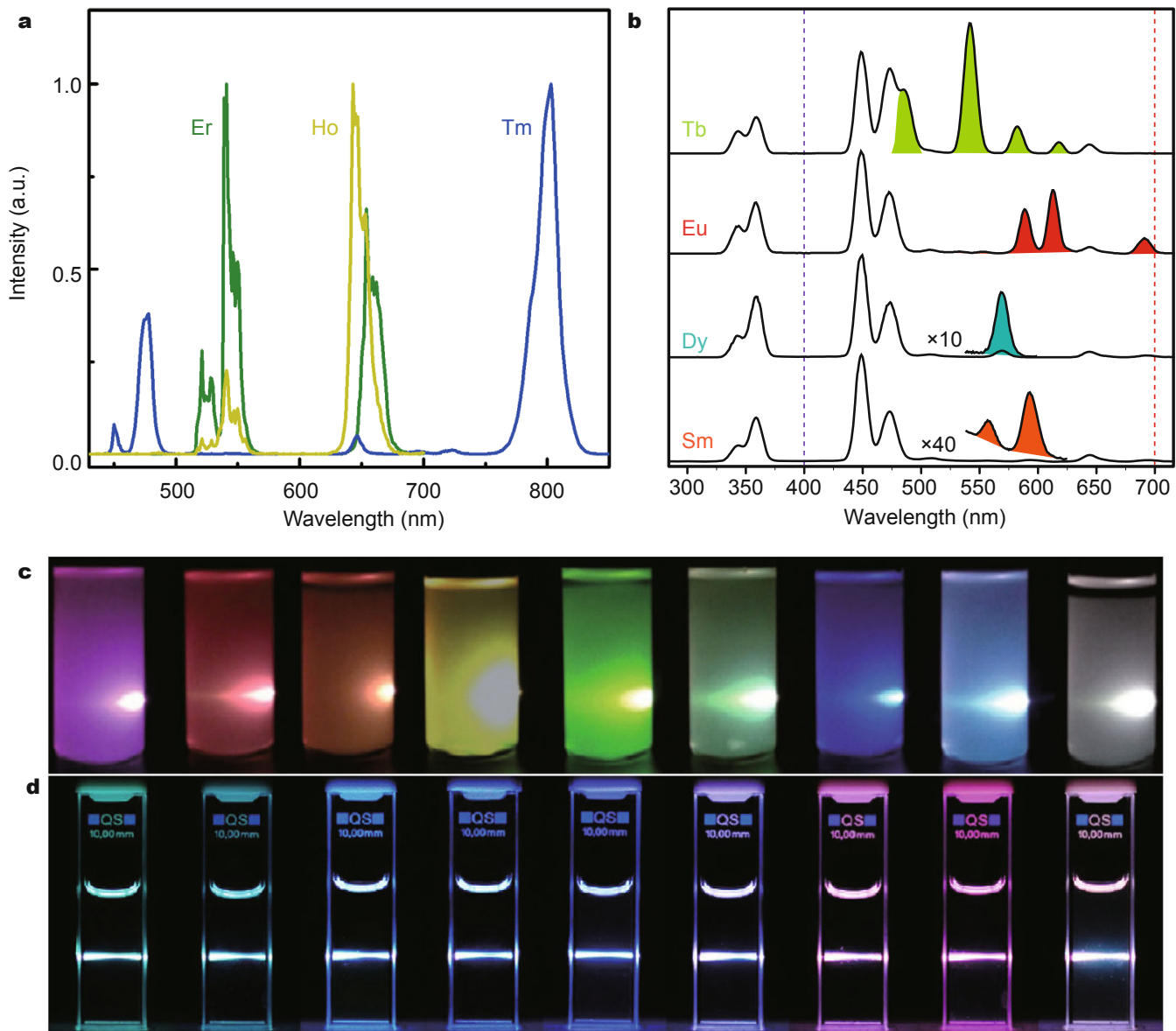

Figure 6 (a) Emission spectra of $\mathrm{Yb} / \mathrm{Er}, \mathrm{Yb} / \mathrm{Ho}$, and $\mathrm{Yb} / \mathrm{Tm}$ co-doped $\mathrm{NaYF}_{4} \mathrm{NPs}_{\mathrm{s}}$ under $980 \mathrm{~nm}$ excitation. Note that all the emission spectra were normalized at their maximal emission peaks. (b) Emission spectra of $\mathrm{NaGdF}_{4}: \mathrm{Yb}, \mathrm{Tm} @ \mathrm{NaGdF}_{4}: \operatorname{Ln}^{3+}(\mathrm{Ln}=\mathrm{Tb}, \mathrm{Eu}$, Dy, and Sm) core-shell NPs for EMU (Adapted with permission from Ref. [115]. Copyright 2011, Macmillan Publishers Limited). Photographs showing the multicolor tuning of UCNPs via (c) ETU (Adapted with permission from Ref. [157]. Copyright 2014, Macmillan Publishers Limited) and (d) EMU (Adapted with permission from Ref. [163]. Copyright 2012, American Chemical Society). 
was realized in $\mathrm{KMnF}_{3}: \mathrm{Ln}^{3+}$ and $\mathrm{NaYF}_{4}: \mathrm{Ln}^{3+}, \mathrm{Mn}^{2+} \mathrm{UCNP}$ $[159,160] . \mathrm{Mn}^{2+}$ ions can also serve as activators with the sensitization of $\mathrm{Yb}^{3+}$ to generate broad-band UCL or as a bridge of energy transfer from $\mathrm{Yb}^{3+}$ to $\mathrm{Eu}^{3+}$ to yield pure $\mathrm{Eu}^{3+} \mathrm{UCL}[161,162]$. The UCL of $\mathrm{Eu}^{3+}$ as well as other DSL emitters like $\mathrm{Tb}^{3+}, \mathrm{Sm}^{3+}$ and $\mathrm{Dy}^{3+}$ that lack of long-lived intermediary energy levels matchable to $\mathrm{Yb}^{3+}$, can also be realized through a novel energy migration-mediated UC (EMU) process (Figs $6 b$ and d) $[59,115,163]$. Such UCL of $\mathrm{Mn}^{2+}$ and $\mathrm{Ln}^{3+}$ ions, which is inaccessible in traditional $\mathrm{Ln}^{3+}$-activated UCNPs, provide new opportunity and flexibility for the optical design of $\mathrm{Ln}^{3+}$-doped UCNPs. Additionally, the excitation wavelength of $\mathrm{Ln}^{3+}$-doped UCNPs can be broadened or shifted beyond $980 \mathrm{~nm}$ by utilizing the absorptions of other $\mathrm{Ln}^{3+}$ ions (e.g., $\mathrm{Er}^{3+}$ at $\sim 1530 \mathrm{~nm}$, $\mathrm{Ho}^{3+}$ at $\sim 1160 \mathrm{~nm}$, or $\mathrm{Nd}^{3+}$ at $\sim 808 \mathrm{~nm}$ ) or by introducing external fluorophores (e.g., NIR dyes) as antennae [164172]. In particular, the newly-developed $\mathrm{Nd}^{3+}$-sensitized UCNPs are more advantageous for in vivo bioimaging than common $\mathrm{Yb}^{3+}$-sensitized UCNPs, since the laser-induced tissue overheating effect can be minimized by virtue of the $\mathrm{Nd}^{3+}$ absorption at $\sim 808 \mathrm{~nm}$ where the water absorption cross-section is much smaller than that at $980 \mathrm{~nm}$ [168172]. Moreover, the commercially available inexpensive $808 \mathrm{~nm}$ NIR diode laser makes $\mathrm{Nd}^{3+}$-sensitized UCNPs more appealing in certain bioapplications.

Currently, the major bottleneck of $\mathrm{Ln}^{3+}$-doped UCNPs towards their commercialization is the relatively low UC QYs due to the nonlinear UC optical nature. Therefore, it is of fundamental significance to improve both the absolute UC QYs and the absorption efficiency of $\mathrm{Ln}^{3+}$-doped UCNPs for practical applications. Several strategies can be exploited to enhance UCL, including multi-wavelength or pulse excitation, crystal-field modification, surface passivation, antenna effect, plasmonic enhancement and external electromagnetic-field enhancement, etc.

\section{Long-lasting phosphorescence}

LLP is an optical phenomenon that the excitation light can be stored by the material within a few minutes followed by slowly releasing upon thermal activation to emitting centers, resulting in light emission that can last for minutes to hours [173]. This phenomenon is also called afterglow or persistent luminescence. LLP is of particular interest for both in vitro biodetection and in vivo bioimaging, because the PLNPs can be excited before signal acquisition, which allows for real-time monitoring of the target analytes for more than $1 \mathrm{~h}$ without the need for any external illumination. Such a removal of in situ excitation in the signal analysis process provides a unique solution to circumvent the interference from tissue autofluorescence and the phototoxicity of the NPs, thereby offering high signal-to-noise ratio and sensitivity for biosensing [174].

In order to interpret the occurrence of LLP, various mechanisms ranging from basic conceptual models to complex systems have been proposed in the past decades [175]. It is generally accepted that upon excitation, charge carriers could be caught by the so called "traps", which are long-lived energy levels inside the band gap of the host material. Initiated by the absorption of thermal energy, the charge carriers are then gradually released from these traps and return to the emitters to produce LLP. For example, in $\mathrm{BaAl}_{2} \mathrm{O}_{4}: \mathrm{Eu}^{2+}, \mathrm{Dy}^{3+}$ phosphors, the introduction of $\mathrm{Dy}^{3+}$ creates trapped centers, and $\mathrm{Eu}^{2+}$ ions act as the emitters via receiving energy from the recombination of electron-hole pairs (Fig. 7a). The excitation energy was firstly accepted by traps and then thermally transferred to $\mathrm{Eu}^{2+}$ to emit photons lasted for several hours [176].

Different from DSL or UCL that are easily achieved in a variety of host materials through $\mathrm{Ln}^{3+}$ doping, LLP can only be produced in rather small number of host matrices. Hitherto, most of the LLP studies focus on a handful of host materials such as aluminates, silicates, sulfides and phosphates [177]. The most famous LLP activators are $\mathrm{Eu}^{2+}$ ions, though some other ions like $\mathrm{Tb}^{3+}, \mathrm{Eu}^{3+}, \mathrm{Mn}^{2+}, \mathrm{Cr}^{3+}$ and $\mathrm{Ti}^{4+}$ were occasionally documented as efficient LLP emitters $[175,178]$. Along with the activators, some rare earth ions (e.g., $\mathrm{Nd}^{3+}, \mathrm{Dy}^{3+}$ ) are frequently co-doped as electron traps to achieve longer and brighter LLP [177]. By proper selection of the host materials and dopant ions, intense and multicolor LLP with afterglows ranging from several minutes to hours can be realized (Fig. 7b) [179].

Besides these traditional visible-emitting LLP phosphors, there has been increasing interest in the development of NIR-emitting PLNPs. The afterglow wavelength of these NPs falls within the tissue transparency window, which is advantageous for long-term in vivo biosensing with deep penetration. For instance, in 2007, le Masne de Chermont and coworkers [32] pioneered the synthesis of $\mathrm{Ca}_{0.2} \mathrm{Zn}_{0.9} \mathrm{Mg}_{0.9} \mathrm{Si}_{2} \mathrm{O}_{6}: \mathrm{Eu}^{2+}, \mathrm{Mn}^{2+}, \mathrm{Dy}^{3+} \mathrm{NPs}$ with broad NIR LLP (600-800 nm) for in vivo imaging for more than $1 \mathrm{~h}$, which is an important milestone for the application of LLP nano-bioprobes. Encouraged by this seminal work, Richard and coworkers [180] demonstrated the first-time use of $\mathrm{CaMgSi}_{2} \mathrm{O}_{6}: \mathrm{Eu}^{2+}, \mathrm{Mn}^{2+}, \mathrm{Pr}^{3+} \mathrm{NPs}$ that exhibited strong NIR LLP at $685 \mathrm{~nm}$ for real-time in vivo bioimaging in mice. Recently, Yan and coworkers [181] realized long-term monitoring of tumors based on $\mathrm{Zn}_{2.94} \mathrm{Ga}_{1.96} \mathrm{Ge}_{2} \mathrm{O}_{10}: \mathrm{Cr}^{3+}, \mathrm{Pr}^{3+}$ PLNPs. Unfortunately, the preparation of all the PLNPs aforementioned requires high-temperature calcination, while their afterglow time is not long enough for longterm in vivo probing yet. Nowadays, the major challenge of PLNPs towards biomedical applications is the synthesis of monodisperse and size-controlled PLNPs. In addition, in 



Figure 7 (a) LLP mechanism of $\mathrm{Eu}^{2+}$ in $\mathrm{BaAl}_{2} \mathrm{O}_{4}: \mathrm{Eu}^{2+}$, Dy ${ }^{3+}$ phosphors (Adapted with permission from Ref. [176]. Copyright 2012, Optical Society of America). (b) The afterglow characteristics of some typical LLP materials as a function of time. The first column represents the light emission of phosphors upon UV irradiation. The second to the tenth columns indicate the afterglows of the samples recorded at 5 min intervals after stopping the UV irradiation (Adapted with permission from Ref. [179]. Copyright 2006, American Chemical Society).

order to improve the afterglow intensity and lasting time, it is also urgent to unravel the trapping and de-trapping mechanisms responsible for LLP in the future.

\section{BACKGROUND-FREE LUMINESCENT BIOASSAY}

By utilizing the long-lived DSL, NIR-triggered anti-Stokes UCL and excitation-free LLP of $\mathrm{Ln}^{3+}$-doped NPs, the background noise from scattered lights and autofluorescence from biological samples can be completely ruled out, thus providing a background-free signal for biodetection and a remarkable sensitivity than conventional fluorescent immunoassays. These NPs can be used either as direct biolabels in heterogeneous assays or as energy transfer donors in homogeneous FRET assays. The analyte concentration in both types of bioassays can be quantified by measuring the PL signal of the NPs labels and the FRET signal, respectively. Based on the unique features of these NPs, a series of sensitive luminescent bioassay techniques, such as hetero- geneous TRPL bioassay, dissolution-enhanced luminescent bioassay (DELBA), UCL bioassay, homogenous TR-FRET, UC-FRET and LLP-FRET assays have been developed in recent years. In this section, we overview the latest progresses of these bioassay techniques based on inorganic lanthanide nanoprobes for background-free luminescent biodetection.

\section{Time-resolved luminescent bioassay}

By employing organic dye rhodamine B isothiocyanate (RBITC) as a phantom of short-lived background fluorescence and $\mathrm{GdF}_{3}: \mathrm{Dy}^{3+} \mathrm{NPs}$ as the nanoprobes, we first demonstrated the effectiveness of the TRPL technique in removing the undesired background noise in 2011 (Fig. 8a) [26]. It was observed that the steady-state PL spectrum for the mixture of $\mathrm{GdF}_{3}: \mathrm{Dy}^{3+}$ and RBITC was dominated by the emission of RBITC upon excitation at $272 \mathrm{~nm}$, whereas only the $\mathrm{Dy}^{3+}$ emission from the NPs was detected in the TRPL spectrum with a delay time of $50 \mu$ s and a gate time 



Figure 8 (a) The measurement principle of TRPL bioassay based on $\mathrm{Ln}^{3+}$-doped NPs. (b) Steady-state and time-resolved (delay time $=50 \mu \mathrm{s}$, gate time $=0.8 \mathrm{~ms}$ ) PL spectra of an aqueous solution containing 0.1 $\mathrm{mM}$ of $\mathrm{GdF}_{3}: \mathrm{Dy}^{3+} \mathrm{NPs}$ and $0.08 \mathrm{mM}$ of RBITC. (c) The PL intensity of RBITC (red) and $\mathrm{GdF}_{3}: \mathrm{Dy}^{3+} \mathrm{NPs}$ (blue) as a function of testing times. Reprinted with permission from Ref. [26]. Copyright 2011, Wiley-VCH Verlag GmbH \& Co. KGaA.

of 0.8 ms (Fig. 8b). Moreover, the PL intensity of RBITC under UV irradiation gradually decreased with the time, whereas that of $\mathrm{GdF}_{3}: \mathrm{Dy}^{3+} \mathrm{NPs}$ kept nearly constant, indicating the superior photostability of $\mathrm{GdF}_{3}: \mathrm{Dy}^{3+} \mathrm{NPs}$ (Fig. 8c). After biotinylation, the $\mathrm{GdF}_{3}: \mathrm{Tb}^{3+} \mathrm{NPs}$ were further explored as sensitive nanoprobes in a heterogeneous TRPL bioassay to detect trace amounts of avidin with a limit of detection (LOD) down to $74 \mathrm{pM}$. On the basis of similar protocol, we have recently extended the TRPL bioassay technique to other $\mathrm{Ln}^{3+}$-NPs like $\mathrm{CaF}_{2}: \mathrm{Ce}, \mathrm{Tb}$ and to the assay of tumor markers such as carcinoembryonic antigen (CEA), alpha-fetoprotein (AFP) and prostate-specific antigen (PSA) with LODs ranging from several to tens of $\mathrm{pM}$ [65].

Besides the application in heterogeneous TRPL bioassays, $\mathrm{Ln}^{3+}$-doped NPs are also regarded as excellent energy donors in homogeneous TR-FRET assays. In a typical TRFRET process, the energy transfer from $\mathrm{Ln}^{3+}$-NP donor will apparently lengthen the PL lifetime of the acceptor such as organic dyes that are intrinsically short-lived, due to the slow population of the acceptor's excited-state from the long-lived $\mathrm{Ln}^{3+}$ 's excited state [27]. When the TR technique is applied, the PL of the acceptor lengthened by the FRET process can be readily distinguished from their intrinsically short-lived PL co-excited under UV excitation. Such a signal screening guarantees both reliability and sensitivi- ty of the assay. By employing biotinylated $\mathrm{NaYF}_{4}: \mathrm{Ce}, \mathrm{Tb}$ NPs as an energy donor and fluorescein isothiocyanate (FITC)-labeled avidin as an energy acceptor, we constructed the first TR-FRET pair for the detection of avidin with an LOD of $4.8 \mathrm{nM}$ [27]. Later on, this novel TR-FRET technique was refined and extended to other $\mathrm{Ln}^{3+}$-NPs such as $\mathrm{KGdF}_{4}: \mathrm{Tb}^{3+}$ and $\mathrm{ZrO}_{2}: \mathrm{Tb}^{3+} \mathrm{NPs}$ for avidin assays with LODs of $\sim 5.5 \mathrm{nM}$ and $\sim 3.0 \mathrm{nM}$, respectively [102,111].

Since the efficiency of nonradiative FRET relies heavily on the distance between the donor and acceptor and competes with the radiative transitions of the donor, small particle size and long PL lifetime of the donor are highly desirable. To maximize the FRET efficiency and achieve a lower detection limit, we developed a unique strategy through sodium co-doping for the synthesis of ultrasmall $(\sim 3.8 \mathrm{~nm})$ and highly emissive (QY of $51 \%) \mathrm{CaF}_{2}: \mathrm{Ce}, \mathrm{Tb}$ NPs with a long PL lifetime ( $12.5 \mathrm{~ms})$ for TR-FRET bioassay [65]. As a proof-of-concept experiment, the biotinylated $\mathrm{CaF}_{2}: \mathrm{Ce}, \mathrm{Tb}$ NPs and FITC-labeled avidin were selected to construct a TR-FRET pair, where the excitation energy was transferred from the NP donor to a nearby acceptor FITC through specific binding (Fig. 9a). As a result, avidin can be quantified by measuring the ratio of the integrated PL intensities of FITC and $\mathrm{Tb}^{3+}$, as denoted by FITC $_{520} /$ $\mathrm{Tb}_{491}$. The FITC ${ }_{520}$ for the TR-FRET signal was gradually enhanced at the expense of the $\mathrm{Tb}_{491}$ signal with the increased amount of avidin (Fig. 9b), indicating the specific binding between avidin and biotin as well as the occurrence of FRET. By contrast, in non-binding control experiments where the biotinylated NPs (or FITC-labeled avidin) were replaced with non-biotinylated NPs (or FITC labeled BSA) under otherwise identical conditions, the TR-FRET signal was hardly observed, thus verifying the high specificity of the assay. Benefiting from the enhanced FRET efficiency through the use of ultrasmall NPs, an improved LOD of $\sim 164$ pM was realized for avidin as compared to previous TR-FRET bioassays (Fig. 9c). Furthermore, for the first time, we explored these TR-FRET nano-bioprobes for the detection of an important tumor marker soluble uPA receptor (suPAR) with an LOD of $\sim 328 \mathrm{pM}$, which is comparable to the serum level in cancer patients (Figs $9 \mathrm{~d}$ and e).

Despite these achievements, inorganic $\mathrm{Ln}^{3+}$-NPs still suffer from a low brightness (i.e., external QY) when compared with $\mathrm{Ln}^{3+}$-chelates due to their weak absorption, which limits their detection sensitivity in bioassays. To circumvent this limitation, the antenna of $\mathrm{Ln}^{3+}$-chelates can be hybridized with $\mathrm{Ln}^{3+}$-NPs to enhance their PL and simultaneously increase the labeling ratio of $\mathrm{Ln}^{3+}$ per biomolecule in bioassays. Following this concept, we recently developed a unique and ultrasensitive bioassay method, namely DEL$\mathrm{BA}$, by simply replacing $\mathrm{Ln}^{3+}$-chelates with inorganic $\mathrm{Ln}^{3+}$ NPs in the labeling process of commercial dissociation-en- 



Figure 9 (a) The principle behind TR-FRET detection. (b) TR-FRET spectra of the bioassay with biotinylated CaF ${ }_{2}$ Ce, Tb NPs as bioprobes as a function of the avidin concentration. (c) Calibration curve for TR-FRET detection: $\mathrm{FITC}_{520} / \mathrm{Tb}_{491}$ ratio of the integrated PL intensities versus the concentration of avidin. The control experiments were conducted with non-biotinylated NPs as bioprobes. (d) TR-FRET spectra of the bioassay with ATFcoupled $\mathrm{CaF}_{2}: \mathrm{Ce}$, Tb NPs as bioprobes as a function of the suPAR concentration. (e) Calibration curve for TR-FRET detection: FITC ${ }_{520} / \mathrm{Tb}_{491}$ versus the concentration of suPAR. The control experiments were conducted with non-ATF-coupled NPs as bioprobes. All spectra in (b) and (d) were normalized at the maximum emission peak at $546 \mathrm{~nm}$. Adapted with permission from Ref. [65]. Copyright 2013, Wiley-VCH Verlag GmbH \& Co. KGaA.

hanced lanthanide fluoroimmunoassay (DELFIA) (Fig. 10) [105]. As a result of the highly concentrated $\mathrm{Ln}^{3+}$ ions in a single NP, a much higher labeling ratio of $\mathrm{Ln}^{3+}$ ions per biomolecule ( 4300 vs. 30) can be achieved. Upon dissolution of the NPs by the enhancer solution, a myriad of $\mathrm{Ln}^{3+}$ ions can be released and transformed into highly luminescent $\mathrm{Ln}^{3+}$ micelles, which significantly amplifies the TRPL signal and thus greatly improves the detection sensitivity. By employing sub-10 $\mathrm{nm} \mathrm{NaEuF}_{4} \mathrm{NPs}$ along with the 2 -naphthoyltrifluoroacetone ( $\beta$-NTA) enhancer solution, an unprecedented amplification ( $10^{6}$ times) of the PL signal of the dissolved NPs was obtained. Utilizing such intense dissolution-enhanced PL, we achieved the detection of CEA in human serum samples with an LOD as low as 0.1 pg mL $\mathrm{m}^{-1}(0.5 \mathrm{fM})$, which was an improvement of 3 orders of magnitude on that of commercial DELFIA. The CEA levels derived from DELBA were compared with those measured independently using a commercial DELFIA kit, and a good agreement was found between both methods (Table 1 ), with a correlation coefficient value of $\sim 0.98$. Parameters including the coefficient of variations (CVs; $<8 \%$ ) and the recoveries (in the range of $95 \%-105 \%$ ) of the assays further confirmed the excellent accuracy and precision of the proposed DELBA. These findings offer new opportunities towards advances in clinical bioassays, thereby opening up new avenues for the exploration of inorganic $\mathrm{Ln}^{3+}$-NPs in versatile bioapplications, such as early-stage cancer diagnosis. 
Table 1 Comparison of the CEA levels in 20 human serum samples independently determined by DELBA based on $\mathrm{NaEuF}_{4}$ NPs and commercial DELFIA kit using Eu ${ }^{3+}$-DTTA complex, respectively. Data represent the mean of three independent experiments. The unit of the CEA levels is $\mathrm{ng} \mathrm{mL}^{-1}[105]$

\begin{tabular}{cccccc}
\hline Samples & DELBA & DELFIA & Samples & DELBA & DELFIA \\
\hline 1 & 133.56 & 127.38 & 11 & 15.12 & 14.71 \\
2 & 15.15 & 17.71 & 12 & 27.88 & 19.63 \\
3 & 32.53 & 29.07 & 13 & 3.13 & 2.97 \\
4 & 27.15 & 15.85 & 14 & 1.19 & 1.24 \\
5 & 53.84 & 44.48 & 15 & 0.68 & 1.03 \\
6 & 52.90 & 63.99 & 16 & 0.52 & 1.05 \\
7 & 11.63 & 5.71 & 17 & 0.96 & 2.29 \\
8 & 25.37 & 31.98 & 18 & 0.65 & 3.01 \\
9 & 20.62 & 11.65 & 19 & 1.16 & 0.45 \\
10 & 12.73 & 5.26 & 20 & 1.82 & 1.03 \\
\hline
\end{tabular}

\section{Upconverting luminescent bioassay}

Since the first demonstration of UCL bioassay in 1999 [182], there has been an extensive research on $\mathrm{Ln}^{3+}$-doped UCNPs in various bioassay applications [183-186]. One representative paradigm was reported by Tanke and coworkers [187], who employed $\mathrm{Y}_{2} \mathrm{O}_{2} \mathrm{~S}: \mathrm{Yb}, \mathrm{Er}$ submicrons as UCL probes in DNA microarrays for the detection of nucleic acid hybrids. Owing to the absence of autofluorescence under NIR excitation, the use of UC phosphors yielded a 4 -fold improved LOD of $1 \mathrm{ng} \mu \mathrm{L}^{-1}$ over that using conventional DSL probe cyanin 5. For point-of-care testing, Hampl, Zuiderwijk and Niedbala et al. [188-190] independently developed a lateral-flow strip for heterogeneous UCL bioassays. In their proof-of-concept experiment, Hampl and coworkers [188] demonstrated the application of $\mathrm{Y}_{2} \mathrm{O}_{2} \mathrm{~S}$ : $\mathrm{Yb}$,Er submicrons as UCL reporters in the lateral-flow strips for the assay of human chorionic gonadotropin (hCG) with an LOD down to $10 \mathrm{pg} \mathrm{mL}^{-1}$, which was at least a 10-fold improvement over the conventional
DSL reporter systems such as colloidal gold or colored latex beads. To amplify the optical signal and improve the detection sensitivity, Wang and $\mathrm{Li}$ [184] proposed a unique UCL bioassay technique through magnetic separation. Specifically, Wang and coworkers [191] developed multiplex aptasensors for the simultaneous detection of three pathogenic bacteria by using aptamer-functionalized multicolor $\mathrm{NaYF}_{4}: \mathrm{Ln}^{3+}$ UCNPs as bioprobes and oligonucleotide-conjugated $\mathrm{Fe}_{3} \mathrm{O}_{4}$ NPs as magnetic separators (Fig. 11). Through magnetic separation and concentration, extremely high sensitivity and selectivity were achieved with LODs of 25, 10, and $15 \mathrm{cfu} \mathrm{mL}^{-1}$ for Staphylococcus aureus, Vibrio parahemolyticus, and Salmonella typhimurium, respectively.

More recently, we designed a novel UCL biodetection system for high-throughput bioassay based on a commercial microplate reader (Synergy 4, BioTek) integrated with a $980 \mathrm{~nm}$ NIR diode laser as the excitation source. By employing the surface-functionalized $\mathrm{Ln}^{3+}$-doped UCNPs as nano-bioprobes, a number of important tumor markers like CEA, AFP, PSA, $\beta$-hCG and suPAR were successfully detected. For instance, utilizing the avidin-functionalized $\mathrm{LiLuF}_{4}: \mathrm{Yb}, \mathrm{Er} @ \mathrm{LiLuF}_{4}$ core-shell UCNPs as the nanoprobes, we realized the detection of $\beta$-hCG in the UCL microplate assay (Fig. 12a) [62]. It was observed that the UCL intensity of the nanoprobes gradually increased with the increased amount of $\beta$-hCG antigen and exhibited a linear dependence with the concentration of $\beta$-hCG at $0-310$ ng $\mathrm{mL}^{-1}$ (Figs $12 \mathrm{~b}$ and c). For comparison, in non-binding control experiment, where BSA instead of $\beta$-hCG antigen was used under otherwise identical conditions, the UCL signal was hardly detectable, thus confirming the high specificity of the assay. The LOD was determined to be $\sim 3.8$ ng $\mathrm{mL}^{-1}$, comparable to the normal range of human serum

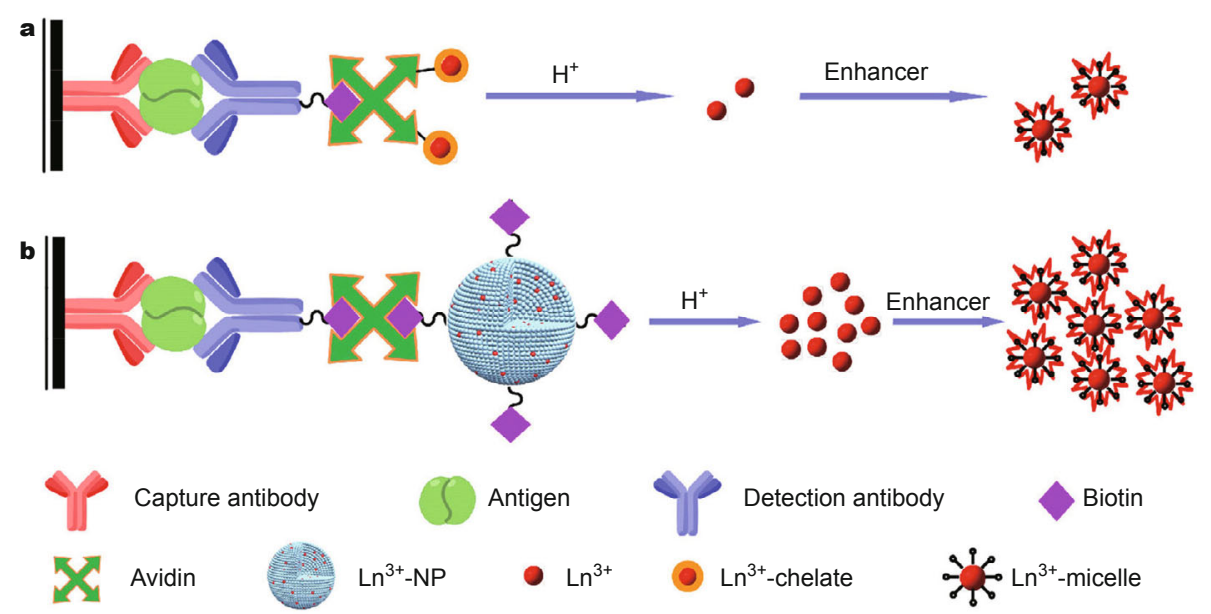

Figure 10 Schematic representation of (a) conventional DELFIA based on $\mathrm{Ln}^{3+}$ chelates and (b) the proposed DELBA based on inorganic $\mathrm{Ln}^{3+}$-NPs. Adapted with permission from Ref. [105]. Copyright 2014, Wiley-VCH Verlag GmbH \& Co. KGaA. 


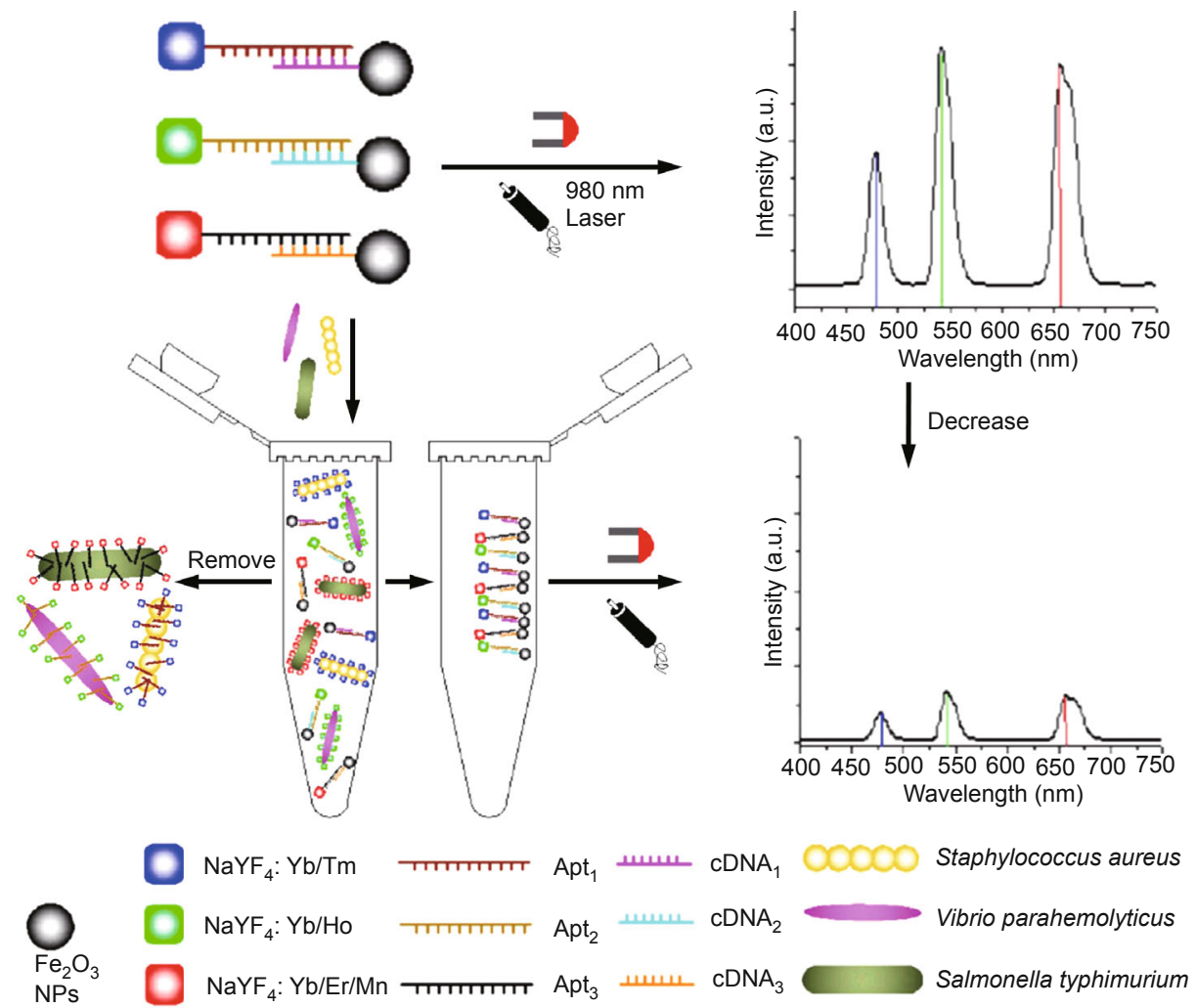

Figure 11 Schematic illustration of multiplexed UCL bioassay based on aptamer-modified UCNPs for the simultaneous detection of various pathogenic bacteria with the assistance of magnetic separation. Reprinted with permission from Ref. [191]. Copyright 2014, American Chemical Society.
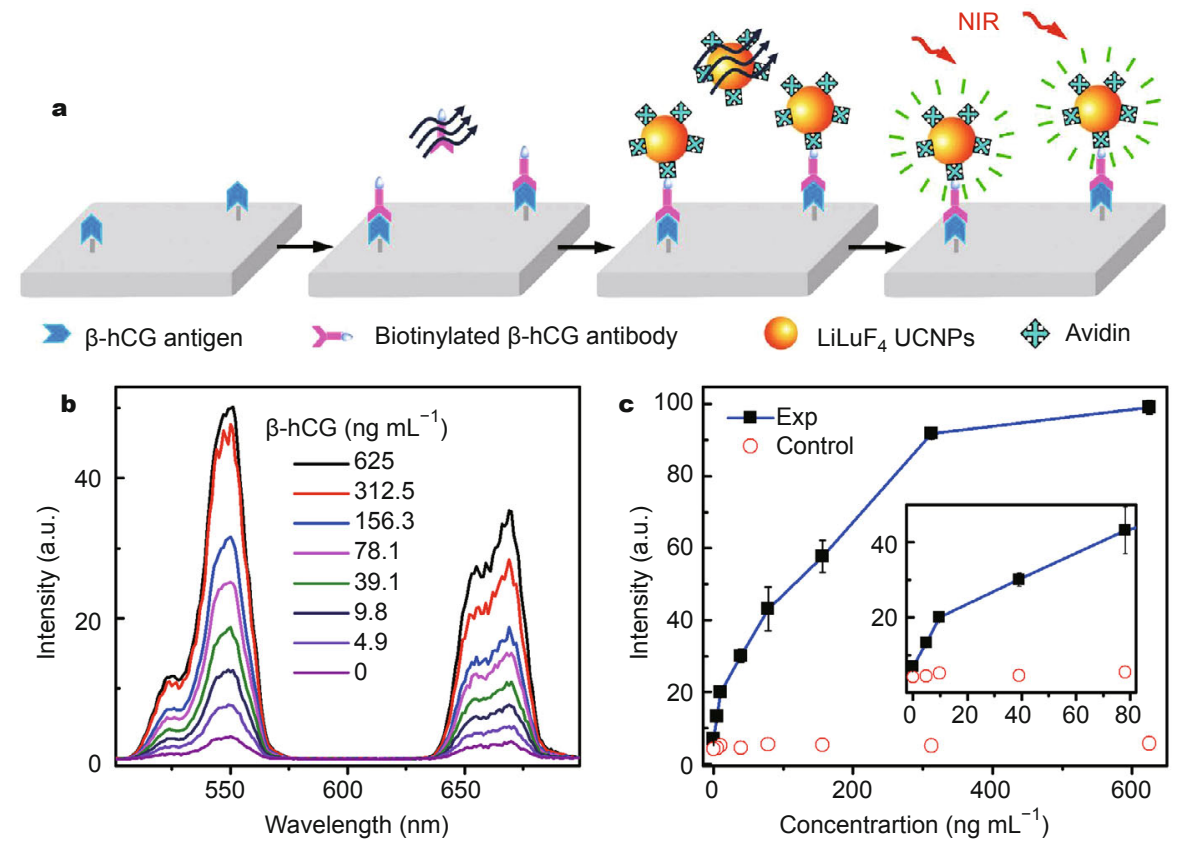

Figure 12 (a) The process and principle of heterogeneous UCL detection of $\beta$-hCG. (b) UCL spectra of the bioassays using LiLuF $\mathrm{Y}_{4} \mathrm{Yb}_{\mathrm{B}, \mathrm{Er} @ \mathrm{LiLuF}}$ core-shell UCNPs with $16 \mathrm{MLs}$ as a function of $\beta$-hCG concentration. (c) Calibration curve of UCL detection for the integrated UCL intensity versus the concentration of $\beta$-hCG. The control experiment was conducted using BSA instead of the $\beta$-hCG antigen as analyte under otherwise identical conditions. Adapted with permission from Ref. [62]. Copyright 2014, Wiley-VCH Verlag GmbH \& Co. KGaA. 


\section{$\beta$-hCG level.}

Apart from functionalizing as direct labels in heterogeneous UCL assays, $\mathrm{Ln}^{3+}$-doped UCNPs are also frequently used as energy donors in homogenous UC-FRET assays $[65,66]$. The UC-FRET assay brings together both advantages of background-free signal from the UCNP donor and separation-free convenience from the homogeneous FRET assay, thus is considered as one of the most convenient bioassay methods for fast detection in practical applications. In a typical UC-FRET process, NIR excitation of the UCNP donor triggers an energy transfer from the donor to a nearby acceptor through molecular recognition, leading to the luminescence quenching of the donor or the emission of the acceptor, subject to the type of acceptor used (fluorescent or not). The commonly used acceptors are those molecules or nanomaterials with a large absorption band overlapped with the emission bands of UCNPs. For instance, based on different acceptor entities such as organic dyes, $\mathrm{Au} \mathrm{NPs}, \mathrm{MnO}_{2}$ nanosheets, carbon NPs, graphene and graphene oxide (GO), Liu and coworkers [192-200] proposed a series of UC-FRET pairs for the detection of diverse biomolecules including glucose, thrombin, DNA, matrix metalloproteinase-2 (MMP-2), CEA, and Kanamycin, etc. For point-of-care testing, they further designed a straightforward paper-based microfluidic device (namely UC- $\mu$ PAD) for UC-FRET assays based on a normal office printing sheet with a simple plotting method [192]. Similar paper-based UC-FRET platforms were also developed by Krull and coworkers [201,202] for DNA hybridization assays.

For the detection of human immunodeficiency virus (HIV) antibody, Chu and coworkers [185] designed an UC-FRET biosensor by using the peptide-functionalized $\mathrm{NaYF}_{4}$ : $\mathrm{Yb}$,Er UCNPs as energy donors and GO as energy quenchers. The UCNP donors were initially adsorbed on the surface of GO via $\pi-\pi$ stacking interactions and hydrophobic interactions between the peptides and GO, which resulted in a complete UCL quenching of the donor through energy transfer or electron transfer processes. Upon addition of anti-HIV-1 gp120 antibody, the adsorption was cleaved through the formation of peptide-antibody complexes, leading to the decrease in quenching efficiency and the recovery of UCL (Fig. 13a). It was observed that the UCL intensity of the nanoprobes increased linearly with the increased concentration of HIV-1 antibody in the range from 5 to $150 \mathrm{nM}$, and the LOD was calculated to be $2 \mathrm{nM}$ according to the $3 \sigma$ rule (Figs $13 \mathrm{~b}$ and c). Similarly, by employing $\beta$-cyclodextrin ( $\beta$-CD) derivative-modified $\mathrm{NaYF}_{4}$ :Yb,Er UCNPs (CD-Cit-UCNPs) as the energy donor and rhodamine $\mathrm{B}(\mathrm{RB})$ as the energy quencher, Ding and coworkers [203] developed a novel UC-FRET platform for the sensing of cholesterol (Cho) (Fig. 14). At the beginning, $\beta$-CD inclusion of RB (RB-CD-Cit-UCNPs) initiated the FRET process due to the close contact between the donor and nearby quencher, resulting in the quenching of the green UCL (515-565 nm) of the donor. Upon addition of cholesterol, the FRET was switched off as a result of the cholesterol-induced release of RB from the cavity of $\beta-C D$,
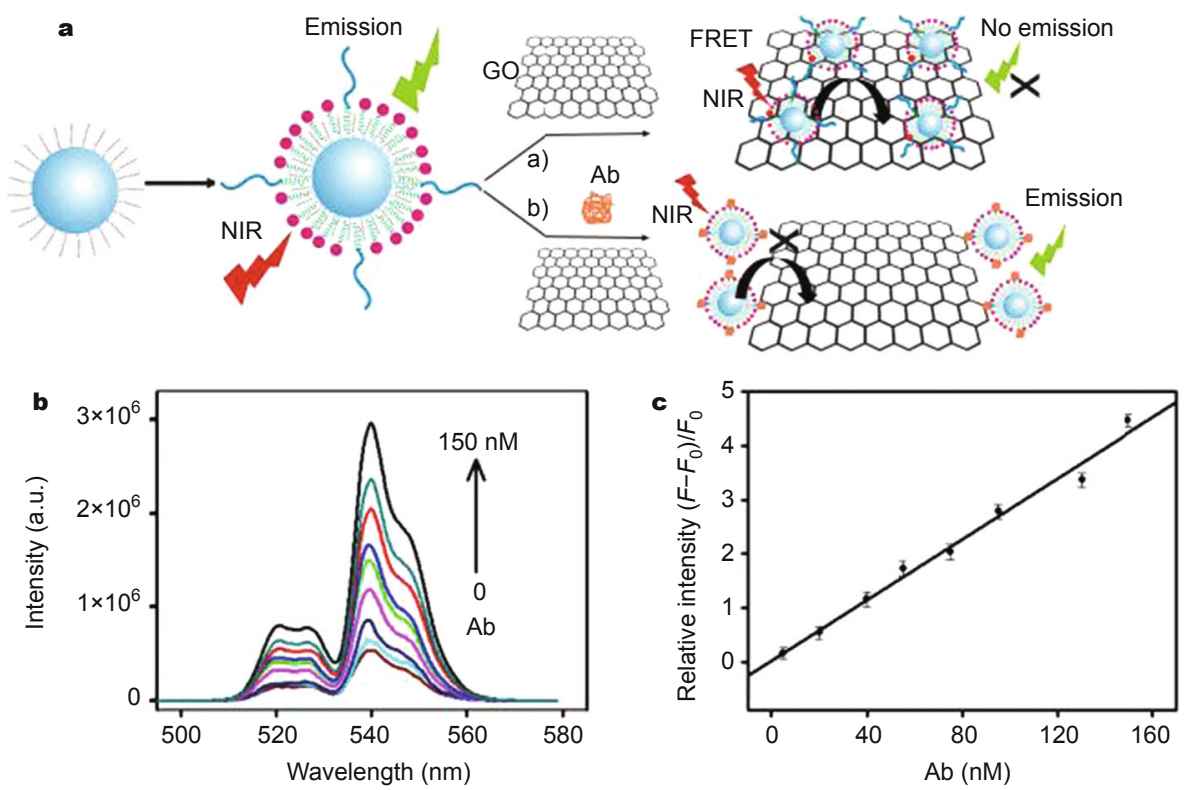

Figure 13 (a) Schematic illustration of the UC-FRET biosensor for anti-HIV-1 gp120 antibody detection. (b) UCL spectra of the biosensor with varying concentrations of antibody $(0,5,20,40,55,75,95,130$ and $150 \mathrm{nM})$. (c) Linear relationship between the UCL intensity and the concentration of antibody within the range of 5-150 nM. Adapted with permission from Ref. [185]. Copyright 2014, Royal Society of Chemistry. 




Figure 14 Schematic illustration of the design and synthesis of RB-CD-Cit-UCNPs, and their UCL response to cholesterol. Adapted with permission from Ref. [203]. Copyright 2014, Royal Society of Chemistry.

giving rise to the recovery of the green UCL. By using the red UCL (640-685 $\mathrm{nm}$ ) as an internal reference, ratiometric detection of cholesterol was realized in the dynamic range of $10-110 \mu \mathrm{M}$, with an LOD down to $\sim 3.0 \mu \mathrm{M}$. The cholesterol levels in human serum samples determined by the platform were compared with those measured via enzymatic method and a good agreement was found. These efforts suggest that $\mathrm{Ln}^{3+}$-doped UCNPs are excellent donor labels in homogeneous FRET assays and may play a critical role in clinical, food and environmental monitoring.

\section{Persistent luminescent bioassay}

The rapid advances in the field of PLNPs open a new avenue for background-free luminescent bioassays. With the benefit of afterglow nature, the PLNPs allow optical excitation before signal acquisition and thus permit biodetection without real-time external illumination, which provides a unique solution to overcome the interference of excitation light and biological autofluorescence arising from in situ excitation [30-32].

The concept of bioassay based on PLNPs was first demonstrated by Yan and coworkers [30] for the detection of AFP in a homogeneous LLP-FRET assay. In their pioneering work, PEI-capped $\mathrm{Ca}_{1.86} \mathrm{Mg}_{0.14} \mathrm{ZnSi}_{2} \mathrm{O}_{7}: \mathrm{Eu}^{2+}$, $\mathrm{Dy}^{3+}$ PLNPs and AFP antibody-conjugated Au NPs were selected as the energy donor and quencher, respectively, to construct an inhibition FRET pair. The FRET process was initiated between the energy donor and quencher in close proximity via electrostatic interaction, giving rise to the quenching of LLP of the donor centered at $\sim 521 \mathrm{~nm}$. Once AFP was added, such a FRET process was inhibited due to desorption of Au NPs from the PLNPs, resulting in an obvious recovery of the LLP intensity (Fig. 15a). As a result, AFP can be quantified by directly measuring the enhanced LLP intensity. Note that the PLNP donor was irradiated for $10 \mathrm{~min}$ before detection to eliminate the need for further excitation during the PL analysis. It was observed that the LLP intensity of the PLNPs increased linearly with the added AFP concentration in the range from 0.8 to $45.0 \mu \mathrm{g} \mathrm{L}^{-1}$ with a correlation coefficient of 0.990 (Figs $15 \mathrm{~b}$ and $\mathrm{c}$ ). The LOD was determined to be $0.41 \mu \mathrm{g} \mathrm{L}^{-1}$, comparable to those of most fluorescent and electrochemical sensors for AFP. The AFP levels in six human serum samples were also detected, which agreed well with those measured independently using a commercial ELISA kit. However, the poor dispersibility and broad size distribution of the PLNPs synthesized at a high temperature may severely deteriorate their detection sensitivity and reliability in practical applications. To increase the sensitivity and reliability of persistent luminescent assay, monodisperse and uniform-sized PLNPs with a high LLP intensity and a long afterglow time are highly demanded. To this end, wet chemical synthesis of PLNPs at lower temperature may be a good option, though it is currently of great challenge. 

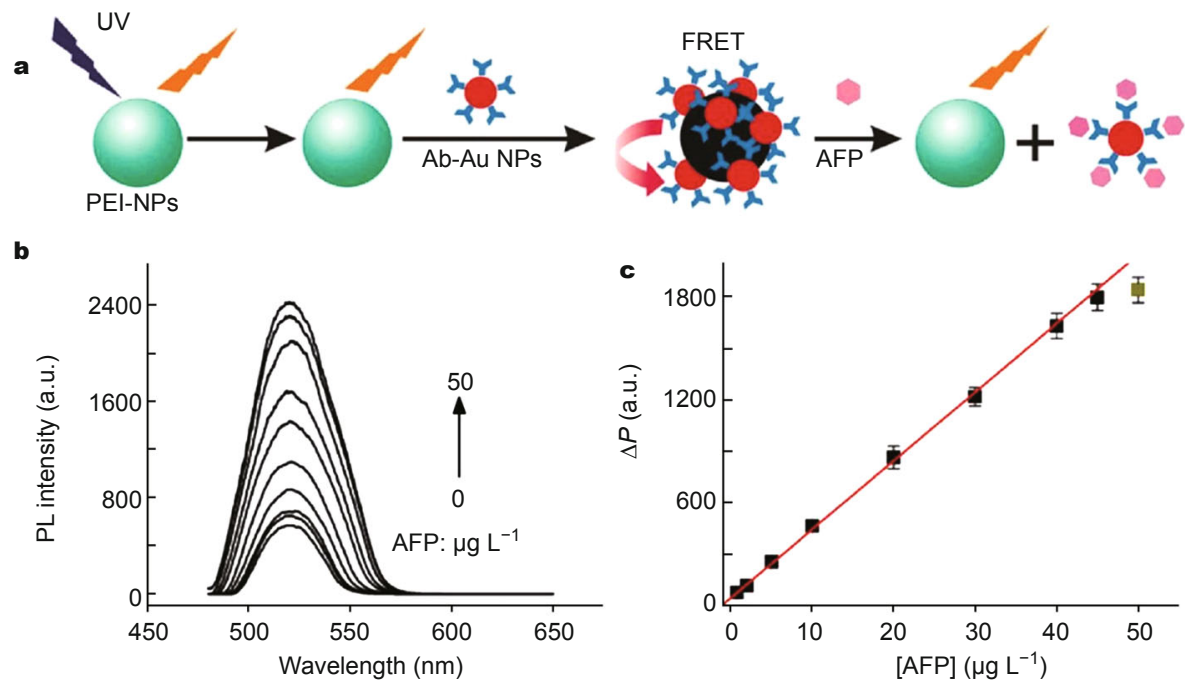

Figure 15 (a) Schematic illustration of the FRET inhibition assay for AFP based on the LLP quenching of PEI-modified PLNPs by AFP antibody-conjugated Au NPs. (b) Effect of AFP concentration on the LLP intensity of PLNPs. (c) Plot of enhanced LLP intensity ( $\triangle P$ ) against AFP concentration over the linear range $0.8-45.0 \mu \mathrm{g} \mathrm{L}{ }^{-1}$. Adapted with permission from Ref. [30]. Copyright 2011, American Chemical Society.

\section{CONCLUSIONS AND PROSPECTS}

Inorganic $\mathrm{Ln}^{3+}$-doped NPs have received extensive interest in recent years because of their excellent physicochemical characteristics, which make them extremely suitable for use as alternative to traditional fluorescent bioprobes like organic dyes, $\mathrm{Ln}^{3+}$-chelates and QDs for background-free luminescent bioassays. These nano-bioprobes, while being in its infancy, have been rapidly developed and pushed forward to a new horizon for diverse bioassays. Substantial progresses have been gained very recently, for their size/ morphology control, functionalization design, optical property optimization as well as their applications for background-free luminescent bioassays. Meanwhile, it remains many new challenges to be solved in an effort to fulfill all requirements for commercial applications.

Firstly, it is fundamentally important to develop general and economic protocols for the synthesis, surface modification and bioconjugation of high-quality $\mathrm{Ln}^{3+}$-doped luminescent nanoprobes that are optimized for bioassay applications without any concerns of biocompatibility, stability and long-term toxicity. It is highly demanded to establish a wet chemical synthetic route for the fabrication of monodisperse and uniform-sized PLNPs. Secondly, the PL efficiency of $\mathrm{Ln}^{3+}$-doped NPs should be further improved in order to increase their detection sensitivity for diverse disease biomarkers. To this end, the antenna ligand that has very large extinction coefficient might be exploited as the sensitizer to enhance their external DSL and UCL efficiency. The capability of energy storage of PLNPs can be controlled through cation incorporation and the choice of novel host materials so as to enhance their LLP intensity and lengthen the afterglow time. Thirdly, with the growing demands for in vivo tracking and imaging of biological activities, it is highly desirable to developed NIR luminescent bioprobes. $\mathrm{Ln}^{3+}$-doped NIR TRPL and LLP NPs are favorable for this purpose in view of their high PL efficiencies. Last but not the least, thanks to their extremely high sensitivity, all background-free luminescent bioassay techniques based on inorganic lanthanide nanoprobes such as DELBA can be further explored for non-invasive analysis of human glandular secretions such as saliva and urine where the analyte concentration might be orders of magnitude lower than in human serum. Such saliva or urine based bioassays may bring new opportunity for early detection or screening of cancer, and would ultimately revolutionize current serum-based bioassays in future community or family medical service.

Received 28 November 2014; accepted 28 December 2014 published online 4 February 2015

1 Bayley H, Cremer PS. Stochastic sensors inspired by biology. Nature, 2001, 413: 226-230

2 Tu DT, Zheng W, Liu YS, et al. Luminescent biodetection based on lanthanide-doped inorganic nanoprobes. Coord Chem Rev, 2014, 273-274: 13-29

3 Weiss A, Abramowski D, Bibel M, et al. Single-step detection of mutant huntingtin in animal and human tissues: a bioassay for huntington's disease. Anal Biochem, 2009, 395: 8-15

4 Borisov SM, Wolfbeis OS. Optical biosensors. Chem Rev, 2008, 108: 423-461

5 Wang XD, Wolfbeis OS, Meier RJ. Luminescent probes and sensors for temperature. Chem Soc Rev, 2013, 42: 7834-7869

6 Zhou V, Han S, Brinker A, et al. A time-resolved fluorescence resonance energy transfer-based hts assay and a surface plasmon res- 
onance-based binding assay for heat shock protein 90 inhibitors. Anal Biochem, 2004, 331: 349-357

7 Lequin RM. Enzyme immunoassay enzyme-linked immunosorbent assay. Clin Chem, 2005, 51: 2415-2418

8 Rissin DM, Kan CW, Campbell TG, et al. Single-molecule enzymelinked immunosorbent assay detects serum proteins at subfemtomolar concentrations. Nat Biotech, 2010, 28: 595-599

9 Clapp AR, Medintz IL, Mauro JM, et al. Fluorescence resonance energy transfer between quantum dot donors and dye-labeled protein acceptors. J Am Chem Soc, 2003, 126: 301-310

10 Medintz IL, Clapp AR, Brunel FM, et al. Proteolytic activity monitored by fluorescence resonance energy transfer through quantum-dot-peptide conjugates. Nat Mater, 2006, 5: 581-589

11 Geißler D, Stufler S, Löhmannsröben H-G, et al. Six-color timeresolved Förster resonance energy transfer for ultrasensitive multiplexed biosensing. J Am Chem Soc, 2012, 135: 1102-1109

12 Luo S, Zhang E, Su Y, et al. A review of NIR dyes in cancer targeting and imaging. Biomaterials, 2011, 32: 7127-7138

13 Gao X, Cui Y, Levenson RM, et al. In vivo cancer targeting and imaging with semiconductor quantum dots. Nat Biotech, 2004, 22 969-976

14 Medintz IL, Uyeda HT, Goldman ER, et al. Quantum dot bioconjugates for imaging, labelling and sensing. Nat Mater, 2005, 4: 435-446

15 Ju Q, Tu DT, Liu YS, et al. Lanthanide-doped inorganic nanocrystals as luminescent biolabels. Comb Chem High T Scr, 2012, 15 580-594

16 Liu YS, Tu DT, Zhu HM, et al. Lanthanide-doped luminescent nano-bioprobes: from fundamentals to biodetection. Nanoscale, 2013 5: $1369-1384$

17 Bunzli JCG. Lanthanide luminescence for biomedical analyses and imaging. Chem Rev, 2010, 110: 2729-2755

18 Huang X, Jain PK, El-Sayed IH, et al. Gold nanoparticles: interesting optical properties and recent applications in cancer diagnostics and therapy. Nanomedicine, 2007, 2: 681-693

19 Bindhani BK, Parida UK, Biswal SK, et al. Gold nanoparticles and their biomedical applications. Rev Nanosci Nanotechnol, 2013, 2 247-260

20 Ray SC, Saha A, Jana NR, et al. Fluorescent carbon nanoparticles: synthesis, characterization, and bioimaging application. J Phys Chem C, 2009, 113: 18546-18551

21 Park S, Ruoff RS. Chemical methods for the production of graphenes. Nat Nanotechnol, 2009, 4: 217-224

22 Liu Z, Tabakman S, Sherlock S, et al. Multiplexed five-color molecular imaging of cancer cells and tumor tissues with carbon nanotube raman tags in the near-infrared. Nano Res, 2010, 3: 222-233

23 Kamaly N, Xiao ZY, Valencia PM, et al. Targeted polymeric therapeutic nanoparticles: design, development and clinical translation. Chem Soc Rev, 2012, 41: 2971-3010

24 Wang J, Liu GD, Engelhard MH, et al. Sensitive immunoassay of a biomarker tumor necrosis factor-alpha based on poly(guanine)-functionalized silica nanoparticle label. Anal Chem, 2006, 78: 6974-6979

25 Liu YS, Tu DT, Zhu HM, et al. Lanthanide-doped luminescent nanoprobes: controlled synthesis, optical spectroscopy, and bioapplications. Chem Soc Rev, 2013, 42: 6924-6958

26 Ju Q, Liu YS, Tu DT, et al. Lanthanide-doped multicolor $\mathrm{GdF}_{3}$ nanocrystals for time-resolved photoluminescent biodetection. ChemEur J, 2011, 17: 8549-8554

27 Tu DT, Liu LQ, Ju Q, et al. Time-resolved fret biosensor based on amine-functionalized lanthanide-doped $\mathrm{NaYF}_{4}$ nanocrystals. Angew Chem Int Ed, 2011, 50: 6306-6310

28 Chen GY, Qiu HL, Prasad PN, et al. Upconversion nanoparticles: design, nanochemistry, and applications in theranostics. Chem Rev, 2014, 114: 5161-5214
29 Zheng W, Huang P, Tu DT, et al. Lanthanide-doped upconversion nano-bioprobes: electronic structures, optical properties, and biodetection. Chem Soc Rev, doi: 10.1039/c4cs00178h

30 Wu BY, Wang HF, Chen JT, et al. Fluorescence resonance energy transfer inhibition assay for $\alpha$-fetoprotein excreted during cancer cell growth using functionalized persistent luminescence nanoparticles. J Am Chem Soc, 2011, 133: 686-688

31 Maldiney T, Bessiere A, Seguin J, et al. The in vivo activation of persistent nanophosphors for optical imaging of vascularization, tumours and grafted cells. Nat Mater, 2014, 13: 418-426

32 le Masne de Chermont Q, Chaneac C, Seguin J, et al. Nanoprobes with near-infrared persistent luminescence for in vivo imaging. Proc Natl Acad Sci USA, 2007, 104: 9266-9271

33 Longmire M, Choyke PL, Kobayashi H. Clearance properties of nano-sized particles and molecules as imaging agents: considerations and caveats. Nanomedicine, 2008, 3: 703-717

34 Sun Y, Feng W, Yang P, et al. The biosafety of lanthanide upconversion nanomaterials. Chem Soc Rev, doi: 10.1039/C4CS00175C

35 Liu CY, Hou Y, Gao MY. Are rare-earth nanoparticles suitable for in vivo applications? Adv Mater, 2014, 26: 6922-6932

36 Peng J, Sun Y, Liu Q, et al. Upconversion nanoparticles dramatically promote plant growth without toxicity. Nano Res, 2012, 5: 770-782

37 Wang G, Peng Q, Li Y. Lanthanide-doped nanocrystals: synthesis, optical-magnetic properties, and applications. Acc Chem Res, 2011, 44: 322-332

38 Gai SL, Li CX, Yang PP, et al. Recent progress in rare earth micro/ nanocrystals: soft chemical synthesis, luminescent properties, and biomedical applications. Chem Rev, 2014, 114: 2343-2389

39 Li X, Zhang F, Zhao D. Lab on upconversion nanoparticles: optical properties and applications engineering via designed nanostructure. Chem Soc Rev, doi: 10.1039/C4CS00163J

40 Cheng L, Yang K, Zhang S, et al. Highly-sensitive multiplexed in vivo imaging using pegylated upconversion nanoparticles. Nano Res, 2010, 3: 722-732

41 Deng $\mathrm{M}, \mathrm{Ma} \mathrm{Y}, \mathrm{Huang} \mathrm{S}$, et al. Monodisperse upconversion $\mathrm{NaYF}_{4}$ nanocrystals: syntheses and bioapplications. Nano Res, 2011, 4: 685-694

$42 \mathrm{Xu} \mathrm{Z}$, Lin J. Hydrothermal synthesis, morphology control and luminescent properties of nano/microstructured rare earth oxide species. Rev Nanosci Nanotechnol, 2013, 2: 225-246

43 Mai HX, Zhang YW, Si R, et al. High-quality sodium rare-earth fluoride nanocrystals: controlled synthesis and optical properties. J Am Chem Soc, 2006, 128: 6426-6436

44 Boyer JC, Vetrone F, Cuccia LA, et al. Synthesis of colloidal upconverting $\mathrm{NaYF}_{4}$ nanocrystals doped with $\mathrm{Er}^{3+}, \mathrm{Yb}^{3+}$ and $\mathrm{Tm}^{3+}, \mathrm{Yb}^{3+}$ via thermal decomposition of lanthanide trifluoroacetate precursors. J Am Chem Soc, 2006, 128: 7444-7445

45 Yi GS, Chow GM. Synthesis of hexagonal-phase $\mathrm{NaYF}_{4}: \mathrm{Yb}$,Er and $\mathrm{NaYF}_{4}: \mathrm{Yb}, \mathrm{Tm}$ nanocrystals with efficient up-conversion fluorescence. Adv Funct Mater, 2006, 16: 2324-2329

46 Ye XC, Collins JE, Kang YJ, et al. Morphologically controlled synthesis of colloidal upconversion nanophosphors and their shapedirected self-assembly. Proc Natl Acad Sci USA, 2010, 107: 2243022435

47 Li ZQ, Zhang Y. An efficient and user-friendly method for the synthesis of hexagonal-phase $\mathrm{NaYF}_{4}$ : $\mathrm{Yb}, \mathrm{Er} / \mathrm{Tm}$ nanocrystals with controllable shape and upconversion fluorescence. Nanotechnology, 2008, 19: 345606

48 Wang F, Deng R, Liu X. Preparation of core-shell $\mathrm{NaGdF}_{4}$ nanoparticles doped with luminescent lanthanide ions to be used as upconversion-based probes. Nat Protoc, 2014, 9: 1634-1644

49 Li X, Wang R, Zhang F, et al. Engineering homogeneous doping in single nanoparticle to enhance upconversion efficiency. Nano Lett, 2014, 14: 3634-3639

50 Wang X, Zhuang J, Peng Q, et al. A general strategy for nanocrystal 
synthesis. Nature, 2005, 437: 121-124

51 Chen DQ, Yu YL, Huang F, et al. Modifying the size and shape of monodisperse bifunctional alkaline-earth fluoride nanocrystals through lanthanide doping. J Am Chem Soc, 2010, 132: 9976-9978

$52 \mathrm{Li}$ CX, Lin J. Rare earth fluoride nano-/microcrystals: synthesis, surface modification and application. J Mater Chem, 2010, 20: 6831-6847

53 Yi GS, Lu HC, Zhao SY, et al. Synthesis, characterization, and biological application of size-controlled nanocrystalline $\mathrm{NaYF}_{4}: \mathrm{Yb}$, Er infrared-to-visible up-conversion phosphors. Nano Lett, 2004, 4: 2191-2196

54 Li F, Li C, Liu J, et al. Aqueous phase synthesis of upconversion nanocrystals through layer-by-layer epitaxial growth for in vivo X-ray computed tomography. Nanoscale, 2013, 5: 6950-6959

55 Chen H, Qi B, Moore T, et al. Synthesis of brightly pegylated luminescent magnetic upconversion nanophosphors for deep tissue and dual mri imaging. Small, 2014, 10: 160-168

56 Ju Q, Luo WQ, Liu YS, et al. Poly (acrylic acid)-capped lanthanide-doped $\mathrm{BaFCl}$ nanocrystals: synthesis and optical properties. Nanoscale, 2010, 2: 1208-1212

57 Liu Y, Ju Q, Chen X. Water-soluble lanthanides doped fluoride nanocrystals for biolabeling: materials and photophysics. Rev Nanosci Nanotechnol, 2012, 1: 163-171

58 Tu DT, Liu YS, Zhu HM, et al. Breakdown of crystallographic site symmetry in lanthanide-doped $\mathrm{NaYF}_{4}$ crystals. Angew Chem Int Ed, 2013, 52: 1128-1133

59 Liu YS, Tu DT, Zhu HM, et al. A strategy to achieve efficient dual-mode luminescence of $\mathrm{Eu}^{3+}$ in lanthanides doped multifunctional NaGdF 4 nanocrystals. Adv Mater, 2010, 22: 3266-3271

60 Ai Y, Tu DT, Zheng W, et al. Lanthanide-doped $\mathrm{NaScF}_{4}$ nanoprobes: crystal structure, optical spectroscopy and biodetection. Nanoscale, 2013, 5: 6430-6438

61 Wang M, Chen Z, Zheng W, et al. Lanthanide-doped upconversion nanoparticles electrostatically coupled with photosensitizers for near-infrared-triggered photodynamic therapy. Nanoscale, 2014, 6 : 8274-8282

62 Huang P, Zheng W, Zhou SY, et al. Lanthanide-doped $\mathrm{LiLuF}_{4}$ upconversion nanoprobes for the detection of disease biomarkers. Angew Chem Int Ed, 2014, 53: 1252-1257

63 Wang Y, Liu Y, Xiao Q, et al. Eu ${ }^{3+}$ doped $\mathrm{KYF}_{4}$ nanocrystals: synthesis, electronic structure, and optical properties. Nanoscale, 2011, 3: 3164-3169

64 Liu R, Tu DT, Liu YS, et al. Controlled synthesis and optical spectroscopy of lanthanide-doped $\mathrm{KLaF}_{4}$ nanocrystals. Nanoscale, 2012, 4: 4485-4491

65 Zheng W, Zhou SY, Chen Z, et al. Sub-10 nm lanthanide-doped $\mathrm{CaF}_{2}$ nanoprobes for time-resolved luminescent biodetection. Angew Chem Int Ed, 2013, 52: 6671-6676

66 Yang Y, Tu D, Zheng W, et al. Lanthanide-doped $\mathrm{Sr}_{2} \mathrm{YF}_{7}$ nanoparticles: controlled synthesis, optical spectroscopy and biodetection. Nanoscale, 2014, 6: 11098-11105

67 Wang F, Wang J, Liu XG. Direct evidence of a surface quenching effect on size-dependent luminescence of upconversion nanoparticles. Angew Chem Int Ed, 2010, 49: 7456-7460

68 Johnson NJJ, Veggel FCJM. Sodium lanthanide fluoride core-shell nanocrystals: a general perspective on epitaxial shell growth. Nano Res, 2013, 6: 547-561

69 Zhang C, Lee JY. Prevalence of anisotropic shell growth in rare earth core-shell upconversion nanocrystals. ACS Nano, 2013, 7: 4393-4402

70 Chen X, Peng D, Ju Q, et al. Photon upconversion in core-shell nanoparticles. Chem Soc Rev, doi: 10.1039/c4cs00151f

71 Johnson NJJ, Korinek A, Dong CH, et al. Self-focusing by ostwald ripening: a strategy for layer-by-layer epitaxial growth on upconverting nanocrystals. J Am Chem Soc, 2012, 134: 11068-11071
72 Li XM, Shen DK, Yang JP, et al. Successive layer-by-layer strategy for multi-shell epitaxial growth: shell thickness and doping position dependence in upconverting optical properties. Chem Mater, 2013, 25: $106-112$

73 Voss B, Haase M. Intrinsic focusing of the particle size distribution in colloids containing nanocrystals of two different crystal phases. ACS Nano, 2013, 7: 11242-11254

74 Basiruddin SK, Saha A, Pradhan N, et al. Advances in coating chemistry in deriving soluble functional nanoparticle. J Phys Chem C, 2010, 114: 11009-11017

75 Zhang TR, Ge JP, Hu YP, et al. A general approach for transferring hydrophobic nanocrystals into water. Nano Lett, 2007, 7: 3203-3207

76 Dong AG, Ye XC, Chen J, et al. A generalized ligand-exchange strategy enabling sequential surface functionalization of colloidal nanocrystals. J Am Chem Soc, 2011, 133: 998-1006

77 Liu Y, Chen T, Wu C, et al. Facile surface functionalization of hydrophobic magnetic nanoparticles. J Am Chem Soc, 2014, 136: 12552-12555

78 Chen ZG, Chen HL, Hu H, et al. Versatile synthesis strategy for carboxylic acid-functionalized upconverting nanophosphors as biological labels. J Am Chem Soc, 2008, 130: 3023-3029

79 Zhou HP, $\mathrm{Xu} \mathrm{CH}$, Sun $\mathrm{W}$, et al. Clean and flexible modification strategy for carboxyl/aldehyde-functionalized upconversion nanoparticles and their optical applications. Adv Funct Mater, 2009, 19: 3892-3900

80 Ozin GA, Bogdan N, Vetrone F, et al. Synthesis of ligand-free colloidally stable water dispersible brightly luminescent lanthanidedoped upconverting nanoparticles. Nano Lett, 2011, 11: 835-840

81 Jiang GC, Pichaandi J, Johnson NJJ, et al. An effective polymer cross-linking strategy to obtain stable dispersions of upconverting $\mathrm{NaYF}_{4}$ nanoparticles in buffers and biological growth media for biolabeling applications. Langmuir, 2012, 28: 3239-3247

82 Das GK, Stark DT, Kennedy IM. Potential toxicity of up-converting nanoparticles encapsulated with a bilayer formed by ligand attraction. Langmuir, 2014, 30: 8167-8176

83 Wang LY, Yan RX, Hao ZY, et al. Fluorescence resonant energy transfer biosensor based on upconversion-luminescent nanoparticles. Angew Chem Int Ed, 2005, 44: 6054-6057

84 Wang C, Cheng L, Liu Z. Upconversion nanoparticles for photodynamic therapy and other cancer therapeutics. Theranostics, 2013, 3: $317-330$

85 Idris NM, Gnanasammandhan MK, Zhang J, et al. In vivo photodynamic therapy using upconversion nanoparticles as remotecontrolled nanotransducers. Nat Med, 2012, 18: 1580-1585

86 Liu JN, Bu JW, Bu WB, et al. Real-time in vivo quantitative monitoring of drug release by dual-mode magnetic resonance and upconverted luminescence imaging. Angew Chem Int Ed, 2014, 53: 4551-4555

87 Sedlmeier A, Gorris HH. Surface modification and characterization of photon-upconverting nanoparticles for bioanalytical applications. Chem Soc Rev, doi: 10.1039/C4CS00186A

88 Zhang YJ, Zheng F, Yang TL, et al. Tuning the autophagy-inducing activity of lanthanide-based nanocrystals through specific surfacecoating peptides. Nat Mater, 2012, 11: 817-826

89 Yang PP, Gai SL, Lin J. Functionalized mesoporous silica materials for controlled drug delivery. Chem Soc Rev, 2012, 41: 3679-3698

90 Chen Z, Zhou L, Bing W, et al. Light controlled reversible inversion of nanophosphor-stabilized pickering emulsions for biphasic enantioselective biocatalysis. J Am Chem Soc, 2014, 136: 7498-7504

91 Liu J, Liu Y, Bu W, et al. Ultrasensitive nanosensors based on upconversion nanoparticles for selective hypoxia imaging in vivo upon near-infrared excitation. J Am Chem Soc, 2014, 136: 9701-9709

92 Li Y, Shi J. Hollow-structured mesoporous materials: chemical synthesis, functionalization and applications. Adv Mater, 2014, 26: 3176-3205 
93 Nam J, Won N, Bang J, et al. Surface engineering of inorganic nanoparticles for imaging and therapy. Adv Drug Deliver Rev, 2013, 65: 622-648

94 Meiser F, Cortez C, Caruso F. Biofunctionalization of fluorescent rare-earth-doped lanthanum phosphate colloidal nanoparticles. Angew Chem Int Ed, 2004, 43: 5954-5957

95 Erathodiyil N, Ying JY. Functionalization of inorganic nanoparticles for bioimaging applications. Acc Chem Res, 2011, 44: 925-935

96 Li L-L, Zhang R, Yin L, et al. Biomimetic surface engineering of lanthanide-doped upconversion nanoparticles as versatile bioprobes. Angew Chem, 2012, 124: 6225-6229

97 Xia L, Kong X, Liu X, et al. An upconversion nanoparticle-zinc phthalocyanine based nanophotosensitizer for photodynamic therapy. Biomaterials, 2014, 35: 4146-4156

98 Voliani V, González-Béjar M, Herranz-Pérez V, et al. Orthogonal functionalisation of upconverting $\mathrm{NaYF}_{4}$ nanocrystals. Chem Eur J, 2013, 19: 13538-13546

99 Beyazit S, Ambrosini S, Marchyk N, et al. Versatile synthetic strategy for coating upconverting nanoparticles with polymer shells through localized photopolymerization by using the particles as internal light sources. Angew Chem Int Ed, 2014, 53: 8919-8923

100 Pillai PP, Huda S, Kowalczyk B, et al. Controlled ph stability and adjustable cellular uptake of mixed-charge nanoparticles. J Am Chem Soc, 2013, 135: 6392-6395

101 Li L-L, Wu P, Hwang K, et al. An exceptionally simple strategy for DNA-functionalized up-conversion nanoparticles as biocompatible agents for nanoassembly, DNA delivery, and imaging. J Am Chem Soc, 2013, 135: 2411-2414

102 Liu Y, Zhou S, Tu D, et al. Amine-functionalized lanthanide-doped zirconia nanoparticles: optical spectroscopy, time-resolved fluorescence resonance energy transfer biodetection, and targeted imaging. J Am Chem Soc, 2012, 134: 15083-15090

103 Mader HS, Link M, Achatz DE, et al. Surface-modified upconverting microparticles and nanoparticles for use in click chemistries. Chem Eur J, 2010, 16: 5416-5424

104 Wilhelm S, Hirsch T, Patterson WM, et al. Multicolor upconversion nanoparticles for protein conjugation. Theranostics, 2013, 3 : 239-248

105 Zhou S, Zheng W, Chen Z, et al. Dissolution-enhanced luminescent bioassay based on inorganic lanthanide nanoparticles. Angew Chem Int Ed, 2014, 53: 12489-12502

106 Bunzli JCG. Benefiting from the unique properties of lanthanide ions. Acc Chem Res, 2006, 39: 53-61

107 Bünzli J-CG, Eliseeva SV. Intriguing aspects of lanthanide luminescence. Chem Sci, 2013, 4: 1939-1949

108 Gschneidner KA, Bünzli JCG, Pecharsky VK. Handbook on the Physics and Chemistry of Rare Earths. Access Online via Elsevier, 2007

109 Tanner PA. Some misconceptions concerning the electronic spectra of tri-positive europium and cerium. Chem Soc Rev, 2013, 42: 5090-5101

110 Chen XY, Liu YS, Tu DT. Lanthanide-Doped Luminescent Nanomaterials: from Fundamentals to Bioapplications. Berlin: Springer-Verlag Press, 2014

111 Ju Q, Tu DT, Liu YS, et al. Amine-functionalized lanthanide-doped $\mathrm{KGdF}_{4}$ nanocrystals as potential optical/magnetic multimodal bioprobes. J Am Chem Soc 2012, 134: 1323-1330

112 Wang F, Xue XJ, Liu XG. Multicolor tuning of (In, P)-doped $\mathrm{YVO}_{4}$ nanoparticles by single-wavelength excitation. Angew Chem Int Ed, 2008, 47: 906-909

113 Wang F, Liu XG. Recent advances in the chemistry of lanthanide-doped upconversion nanocrystals. Chem Soc Rev, 2009, 38: 976-989

114 Li CX, Quan ZW, Yang J, et al. Highly uniform and monodisperse $\beta-\mathrm{NaYF}_{4}: \mathrm{Ln}^{3+}(\mathrm{Ln}=\mathrm{Eu}, \mathrm{Tb}, \mathrm{Yb} / \mathrm{Er}$, and $\mathrm{Yb} / \mathrm{Tm})$ hexagonal micro- prism crystals: hydrothermal synthesis and luminescent properties. Inorg Chem, 2007, 46: 6329-6337

115 Wang F, Deng RR, Wang J, et al. Tuning upconversion through energy migration in core-shell nanoparticles. Nat Mater, 2011, 10: 968-973

116 Zheng W, Tu DT, Liu YS, et al. Lanthanide-doped luminescent materi: electronic structures, optical properties, and bioapplications. Sci China Chem, 2014, 44: 168-179

117 Blass G, Grabmaier BC. Luminescent Materials. Berlin: Springer-Verlag, 1994

118 Wang F, Liu XG. Multicolor tuning of lanthanide-doped nanoparticles by single wavelength excitation. Acc Chem Res, 2014, 47: $1378-1385$

119 Blasse G, Bril A. Study of energy transfer from $\mathrm{Sb}^{3+}, \mathrm{Bi}^{3+}, \mathrm{Ce}^{3+}$ to $\mathrm{Sm}^{3+}, \mathrm{Eu}^{3+}, \mathrm{Tb}^{3+}, \mathrm{Dy}^{3+}$. J Chem Phys, 1967, 47: 1920-1924

120 Rabouw FT, den Hartog SA, Senden T, et al. Photonic effects on the Förster resonance energy transfer efficiency. Nat Commun, 2014, 5: 3610

121 Liu YS, Luo WQ, Li RF, et al. Spectroscopic evidence of the multiple-site structure of $\mathrm{Eu}^{3+}$ ions incorporated in $\mathrm{ZnO}$ nanocrystals. Opt Lett, 2007, 32: 566-568

122 Fu C, Liao J, Luo W, et al. Emission of $1.53 \mu \mathrm{m}$ originating from the lattice site of $\mathrm{Er}^{3+}$ ions incorporated in $\mathrm{TiO}_{2}$ nanocrystals. Opt Lett, 2008, 33: 953-955

123 Luo W, Li R, Liu G, et al. Evidence of trivalent europium incorporated in anatase $\mathrm{TiO}_{2}$ nanocrystals with multiple sites. J Phys Chem C, 2008, 112: 10370-10377

124 Kong J, Zhu H, Li R, et al. Carrier-mediated $1.55 \mu \mathrm{m}$ photoluminescence from single $\mathrm{Er}^{3+}$ center in $\mathrm{SnO}_{2}$ nanocrystals. Opt Lett, 2009, 34: $1873-1875$

125 Luo W, Li R, Chen X. Host-sensitized luminescence of $\mathrm{Nd}^{3+}$ and $\mathrm{Sm}^{3+}$ ions incorporated in anatase titania nanocrystals. J Phys Chem C, 2009, 113: 8772-8777

126 Liu YS, Li RF, Luo WQ, et al. Optical spectroscopy of $\mathrm{Sm}^{3+}$ and $\mathrm{Dy}^{3+}$ doped zno nanocrystals. Spectrosc Lett, 2010, 43: 343-349

127 Chen X, Luo W. Optical spectroscopy of rare earth ion-doped $\mathrm{TiO}_{2}$ nanophosphors. J Nanosci Nanotechno, 2010, 10: 1482-1494

128 Xiao QB, Liu YS, Liu LQ, et al. $\mathrm{Eu}^{3+}$-doped $\operatorname{In}_{2} \mathrm{O}_{3}$ nanophosphors: electronic structure and optical characterization. J Phys Chem C, 2010, 114: 9314-9321

129 Liu YS, Luo WQ, Zhu HM, et al. Optical spectroscopy of lanthanides doped in wide band-gap semiconductor nanocrystals. J Lumin, 2011, 131: 415-422

130 Luo WQ, Fu CY, Li RF, et al. $\mathrm{Er}^{3+}$-doped anatase $\mathrm{TiO}_{2}$ nanocrystals: crystal-field levels, excited-state dynamics, upconversion, and defect luminescence. Small, 2011, 7: 3046-3056

131 Tang H, Liu YS, Luo WQ, et al. Optical spectroscopy of $\mathrm{Eu}^{3+}$ ions in tetragonal $\mathrm{ZrO}_{2}$ nanocrystals. J Nanosci Nanotechno, 2011, 11: 9445-9450

132 Zhu H, Li R, Luo W, et al. $\mathrm{Eu}^{3+}$-doped $\beta-\mathrm{Ga}_{2} \mathrm{O}_{3}$ nanophosphors: annealing effect, electronic structure and optical spectroscopy. Phys Chem Chem Phys, 2011, 13: 4411-4419

133 Zheng W, Zhu H, Li R, et al. Visible-to-infrared quantum cutting by phonon-assisted energy transfer in $\mathrm{YPO}_{4}: \mathrm{Tm}^{3+}, \mathrm{Yb}^{3+}$ phosphors. Phys Chem Chem Phys, 2012, 14: 6974-6980

134 Liu Y, Luo W, Li R, et al. Optical properties of $\mathrm{Nd}^{3+}$ ion-doped zno nanocrystals. J Nanosci Nanotechno, 2010, 10: 1871-1876

135 Xiao QB, Zhu HM, Tu DT, et al. Near-infrared-to-near-infrared downshifting and near-infrared-to-visible upconverting luminescence of $\mathrm{Er}^{3+}$-doped $\mathrm{In}_{2} \mathrm{O}_{3}$ nanocrystals. J Phys Chem C, 2013, 117: 10834-10841

136 Li X, Wang $\mathrm{R}$, Zhang $\mathrm{F}$, et al. $\mathrm{Nd}^{3+}$ sensitized up/down converting dual-mode nanomaterials for efficient in-vitro and in-vivo bioimaging excited at $800 \mathrm{~nm}$. Sci Rep, 2013, 3: 3536

137 Wang R, Li X, Zhou L, et al. Epitaxial seeded growth of rare-earth 
nanocrystals with efficient $800 \mathrm{~nm}$ near-infrared to $1525 \mathrm{~nm}$ short-wavelength infrared downconversion photoluminescence for in vivo bioimaging. Angew Chem Int Ed, 2014, 53: 12086-12090

138 Auzel F. Upconversion and anti-stokes processes with $\mathrm{f}$ and $\mathrm{d}$ ions in solids. Chem Rev, 2004, 104: 139-173

139 Krämer KW, Biner D, Frei G, et al. Hexagonal sodium yttrium fluoride based green and blue emitting upconversion phosphors. Chem Mater, 2004, 16: 1244-1251

140 Aebischer A, Hostettler M, Hauser J, et al. Structural and spectroscopic characterization of active sites in a family of light-emitting sodium lanthanide tetrafluorides. Angew Chem Int Ed, 2006, 45: 2802-2806

141 Liu Q, Sun Y, Yang TS, et al. Sub-10 nm hexagonal lanthanide-doped $\mathrm{NaLuF}_{4}$ upconversion nanocrystals for sensitive bioimaging in vivo. J Am Chem Soc, 2011, 133: 17122-17125

142 Peng JJ, Sun Y, Zhao LZ, et al. Polyphosphoric acid capping radioactive/upconverting $\mathrm{NaLuF}_{4}: \mathrm{Yb}, \mathrm{Tm},{ }^{153} \mathrm{Sm}$ nanoparticles for blood pool imaging in vivo. Biomaterials, 2013, 34: 9535-9544

143 Zeng SJ, Wang HB, Lu W, et al. Dual-modal upconversion fluorescent/X-ray imaging using ligand-free hexagonal phase $\mathrm{NaLuF}_{4}: \mathrm{Gd} /$ $\mathrm{Yb} / \mathrm{Er}$ nanorods for blood vessel visualization. Biomaterials, 2014, 35: 2934-2941

144 Haase M, Schafer H. Upconverting nanoparticles. Angew Chem Int Ed, 2011, 50: 5808-5829

145 Gnach A, Bednarkiewicz A. Lanthanide-doped up-converting nanoparticles: merits and challenges. Nano Today, 2012, 7: 532-563

146 Zhu H, Chen X, Jin LM, et al. Amplified spontaneous emission and lasing from lanthanide-doped up-conversion nanocrystals. ACS Nano, 2013, 7: 11420-11426

$147 \mathrm{Xu}$ CT, Zhan QQ, Liu HC, et al. Upconverting nanoparticles for pre-clinical diffuse optical imaging, microscopy and sensing: current trends and future challenges. Laser Photon Rev, 2013, 7: 663697

148 Gu ZJ, Yan L, Tian G, et al. Recent advances in design and fabrication of upconversion nanoparticles and their safe theranostic applications. Adv Mater, 2013, 25: 3758-3779

149 Wang J, Deng RR, MacDonald MA, et al. Enhancing multiphoton upconversion through energy clustering at sublattice level. Nat Mater, 2014, 13: 157-162

150 Sun LD, Wang YF, Yan CH. Paradigms and challenges for bioapplication of rare earth upconversion luminescent nanoparticles: small size and tunable emission/excitation spectra. Acc Chem Res, 2014, 47: 1001-1009

151 Min YZ, Li JM, Liu F, et al. Recent advance of biological molecular imaging based on lanthanide-doped upconversion-luminescent nanomaterials. Nanomaterials, 2014, 4: 129-154

152 Lu YQ, Zhao JB, Zhang R, et al. Tunable lifetime multiplexing using luminescent nanocrystals. Nat Photon, 2014, 8: 32-36

153 Zhang YH, Zhang LX, Deng RR, et al. Multicolor barcoding in a single upconversion crystal. J Am Chem Soc, 2014, 136: 4893-4896

154 Wang F, Liu XG. Upconversion multicolor fine-tuning: visible to near-infrared emission from lanthanide-doped $\mathrm{NaYF}_{4}$ nanoparticles. J Am Chem Soc, 2008, 130: 5642-5643

155 Chen G, Qiu H, Fan R, et al. Lanthanide-doped ultrasmall yttrium fluoride nanoparticles with enhanced multicolor upconversion photoluminescence. J Mater Chem, 2012, 22: 20190-20197

156 Dou QQ, Idris NM, Zhang Y. Sandwich-structured upconversion nanoparticles with tunable color for multiplexed cell labeling. Biomaterials, 2013, 34: 1722-1731

157 Lee J, Bisso PW, Srinivas RL, et al. Universal process-inert encoding architecture for polymer microparticles. Nat Mater, 2014, 13: 524-529

158 Quintanilla M, Ren F, Ma D, et al. Light management in upconverting nanoparticles: ultrasmall core/shell architectures to tune the emission color. ACS Photon, 2014, 1: 662-669
159 Wang J, Wang F, Wang C, et al. Single-band upconversion emission in lanthanide-doped $\mathrm{KMnF}_{3}$ nanocrystals. Angew Chem Int Ed, 2011, 50: 10369-10372

160 Tian G, Gu ZJ, Zhou LJ, et al. $\mathrm{Mn}^{2+}$ dopant-controlled synthesis of $\mathrm{NaYF}_{4}: \mathrm{Yb} / \mathrm{Er}$ upconversion nanoparticles for in vivo imaging and drug delivery. Adv Mater, 2012, 24: 1226-1231

161 Song E, Ding S, Wu M, et al. Anomalous NIR luminescence in $\mathrm{Mn}^{2+}$-doped fluoride perovskite nanocrystals. Adv Opt Mater, 2014, 2: $670-678$

162 Wang Z, Feng J, Song S, et al. Pure and intense orange upconversion luminescence of $\mathrm{Eu}^{3+}$ from the sensitization of $\mathrm{Yb}^{3+}-\mathrm{Mn}^{2+}$ dimer in $\mathrm{NaY}(\mathrm{Lu}) \mathrm{F}_{4}$ nanocrystals. J Mater Chem C, 2014, 2: 9004-9011

163 Su QQ, Han SY, Xie XJ, et al. The effect of surface coating on energy migration-mediated upconversion. J Am Chem Soc, 2012, 134: 20849-20857

164 Chen DQ, Lei L, Yang AP, et al. Ultra-broadband near-infrared excitable upconversion core/shell nanocrystals. Chem Commun, 2012, 48: 5898-5900

165 Zhou JJ, Deng JY, Zhu HM, et al. Up-conversion luminescence in $\mathrm{LaF}_{3}: \mathrm{Ho}^{3+}$ via two-wavelength excitation for use in solar cells. J Mater Chem C, 2013, 1: 8023-8027

166 Zou WQ, Visser C, Maduro JA, et al. Broadband dye-sensitized upconversion of near-infrared light. Nat Photon, 2012, 6: 560-564

167 Chen GY, Ohulchanskyy TY, Kachynski A, et al. Intense visible and near-infrared upconversion photoluminescence in colloidal LiY$\mathrm{F}_{4}: \mathrm{Er}^{3+}$ nanocrystals under excitation at $1490 \mathrm{~nm}$. ACS Nano, 2011, 5: 4981-4986

168 Shen J, Chen GY, Vu A-M, et al. Engineering the upconversion nanoparticle excitation wavelength: cascade sensitization of tridoped upconversion colloidal nanoparticles at $800 \mathrm{~nm}$. Adv Opt Mater, 2013, 1: 644-650

169 Zhong YT, Tian G, Gu ZJ, et al. Elimination of photon quenching by a transition layer to fabricate a quenching-shield sandwich structure for $800 \mathrm{~nm}$ excited upconversion luminescence of $\mathrm{Nd}^{3+}$-sensitized nanoparticles. Adv Mater, 2014, 26: 2831-2837

170 Wen HL, Zhu H, Chen X, et al. Upconverting near-infrared light through energy management in core-shell-shell nanoparticles. Angew Chem Int Ed, 2013, 52: 13419-13423

171 Wang YF, Liu GY, Sun LD, et al. $\mathrm{Nd}^{3+}$-sensitized upconversion nanophosphors: efficient in vivo bioimaging probes with minimized heating effect. ACS Nano, 2013, 7: 7200-7206

172 Xie X, Gao N, Deng R, et al. Mechanistic investigation of photon upconversion in $\mathrm{Nd}^{3+}$-sensitized core-shell nanoparticles. J Am Chem Soc, 2013, 135: 12608-12611

173 Pan ZW, Lu YY, Liu F. Sunlight-activated long-persistent luminescence in the near-infrared from $\mathrm{Cr}^{3+}$-doped zinc gallogermanates. Nat Mater, 2012, 11: 58-63

174 Shi J, Sun X, Li J, et al. Multifunctional near infrared-emitting long-persistence luminescent nanoprobes for drug delivery and targeted tumor imaging. Biomaterials, 2015, 37: 260-270

175 Brito HF, Holsa J, Laamanen T, et al. Persistent luminescence mechanisms: human imagination at work. Opt Mater Express, 2012, 2: 371-381

176 Rodrigues LCV, Brito HF, Holsa J, et al. Persistent luminescence behavior of materials doped with $\mathrm{Eu}^{2+}$ and $\mathrm{Tb}^{3+}$. Opt Mater Express, 2012, 2: 382-390

177 Van den Eeckhout K, Smet PF, Poelman D. Persistent luminescence in $\mathrm{Eu}^{2+}$-doped compounds: a review. Materials, 2010, 3: 2536-2566

178 Chen W. Optical storage based on reversible optical processes in $\mathrm{Eu}^{3+}$ doped nanoparticles. Rev Nanosci Nanotechnol, 2013, 2: 143146

179 Clabau F, Rocquefelte X, Le Mercier T, et al. Formulation of phosphorescence mechanisms in inorganic solids based on a new model of defect conglomeration. Chem Mater, 2006, 18: 3212-3220

180 Maldiney T, Lecointre A, Viana B, et al. Controlling electron trap 
depth to enhance optical properties of persistent luminescence nanoparticles for in vivo imaging. J Am Chem Soc, 2011, 133: 11810-11815

181 Abdukayum A, Chen JT, Zhao Q, et al. Functional near infrared-emitting $\mathrm{Cr}^{3+} / \mathrm{Pr}^{3+}$ co-doped zinc gallogermanate persistent luminescent nanoparticles with superlong afterglow for in vivo targeted bioimaging. J Am Chem Soc, 2013, 135: 14125-14133

182 Zijlmans H, Bonnet J, Burton J, et al. Detection of cell and tissue surface antigens using up-converting phosphors: a new reporter technology. Anal Biochem, 1999, 267: 30-36

183 Wu SJ, Duan N, Wang ZP, et al. Aptamer-functionalized magnetic nanoparticle-based bioassay for the detection of ochratoxin a using upconversion nanoparticles as labels. Analyst, 2011, 136: 2306-2314

184 Wang LY, Li YD. Green upconversion nanocrystals for DNA detection. Chem Comm, 2006, 24: 2557-2859

185 Wu YM, Cen Y, Huang LJ, et al. Upconversion fluorescence resonance energy transfer biosensor for sensitive detection of human immunodeficiency virus antibodies in human serum. Chem Commun, 2014, 50: 4759-4762

186 Wang J, Wei T, Li XY, et al. Near-infrared-light-mediated imaging of latent fingerprints based on molecular recognition. Angew Chem Int Ed, 2014, 53: 1616-1620

187 van de Rijke F, Zijlmans H, Li S, et al. Up-converting phosphor reporters for nucleic acid microarrays. Nat Biotechnol, 2001, 19: 273-276

188 Hampl J, Hall M, Mufti NA, et al. Upconverting phosphor reporters in immunochromatographic assays. Anal Biochem, 2001, 288: 176-187

189 Zuiderwijk M, Tanke HJ, Sam Niedbala R, et al. An amplification-free hybridization-based DNA assay to detect streptococcus pneumoniae utilizing the up-converting phosphor technology. Clin Biochem, 2003, 36: 401-403

190 Niedbala RS, Feindt H, Kardos K, et al. Detection of analytes by immunoassay using up-converting phosphor technology. Anal Biochem, 2001, 293: 22-30

191 Wu SJ, Duan N, Shi Z, et al. Simultaneous aptasensor for multiplex pathogenic bacteria detection based on multicolor upconversion nanoparticles labels. Anal Chem, 2014, 86: 3100-3107

192 He MY, Liu ZH. Paper-based microfluidic device with upconversion fluorescence assay. Anal Chem, 2013, 85: 11691-11694

193 Peng JH, Wang YH, Wang JL, et al. A new biosensor for glucose determination in serum based on up-converting fluorescence resonance energy transfer. Biosens Bioelectron, 2011, 28: 414-420

194 Yuan YX, Wu SF, Shu F, et al. An $\mathrm{mno}_{2}$ nanosheet as a label-free nanoplatform for homogeneous biosensing. Chem Commun, 2014, 50: $1095-1097$

195 Wang YH, Bao L, Liu ZH, et al. Aptamer biosensor based on fluorescence resonance energy transfer from upconverting phosphors to carbon nanoparticles for thrombin detection in human plasma. Anal Chem, 2011, 83: 8130-8137

196 Wu Z, Li H, Liu Z. An aptasensor for carcinoembryonic antigen based on upconversion fluorescence resonance energy transfer. Sensor Actuat B-Chem, 2015, 206: 531-537

197 Li H, Sun D-e, Liu YJ, et al. An ultrasensitive homogeneous aptasensor for kanamycin based on upconversion fluorescence resonance energy transfer. Biosens Bioelectron, 2014, 55: 149-156

198 Zhang CL, Yuan YX, Zhang SM, et al. Biosensing platform based on fluorescence resonance energy transfer from upconverting nanocrystals to graphene oxide. Angew Chem Int Ed, 2011, 50: 6851-6854

199 Wang YH, Wu ZJ, Liu ZH. Upconversion fluorescence resonance energy transfer biosensor with aromatic polymer nanospheres as the lable-free energy acceptor. Anal Chem, 2013, 85: 258-264

200 Wang YH, Shen P, Li CY, et al. Upconversion fluorescence resonance energy transfer based biosensor for ultrasensitive detection of matrix metalloproteinase-2 in blood. Anal Chem, 2012, 84: 1466-1473

201 Zhou F, Noor MO, Krull UJ. Luminescence resonance energy transfer-based nucleic acid hybridization assay on cellulose paper with upconverting phosphor as donors. Anal Chem, 2014, 86: 2719-2726

202 Ju Q, Uddayasankar U, Krull U. Paper-based DNA detection using lanthanide-doped $\mathrm{LiYF}_{4}$ upconversion nanocrystals as bioprobe. Small, 2014, 10: 3912-3917

203 Ding Y, Zhu H, Zhang X, et al. An upconversion nanocomposite for fluorescence resonance energy transfer based cholesterol-sensing in human serum. Nanoscale, 2014, 6: 14792-14798

Acknowledgements This work was supported by the National Basic Research Program of China (2014CB845605), Special Project of National Major Scientific Equipment Development of China (2012YQ120060), the National Natural Science Foundation of China (11204302, 11304314, U1305244, U1405229 and 21325104), the Chinese Academy of Sciences (CAS)/State Administration of Foreign Expert Affairs International Partnership Program for Creative Research Teams, the CAS CrossDisciplinary \& Collaborative Research Team Program, the Strategic Priority Research Program and Scientific Equipment Development Project of the CAS (XDA09030307 and YZ201210), and the Key Project of Science and Technology of Fujian Province (2013H0060).

Author contributions Huang $\mathrm{P}$ and Chen $\mathrm{X}$ wrote the manuscript and designed the figures. Tu D and Zheng $\mathrm{W}$ prepared the materials of fundamental physicochemical properties. Zhou S and Chen Z prepared the materials of bioassay applications. All authors contributed to the general discussion and revision of the manuscript.

Conflict of interest The authors declare that they have no conflict of interest. 


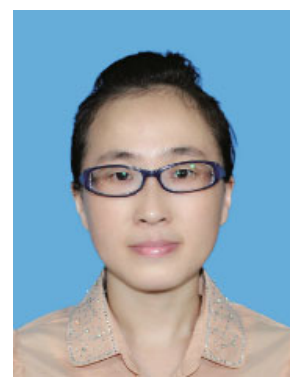

Ping Huang was born in Hebei, China. She received her BSc (2008) from Hebei University, and PhD (2014) in materials physics and chemistry from Fujian Institute of Research on the Structure of Matter (FJIRSM), CAS. She joined Prof. Xueyuan Chen's group as a research assistant professor in July 2014. Her research interest focuses on the chemical synthesis, optical spectroscopy and bioapplications of lanthanide-doped nanoprobes.

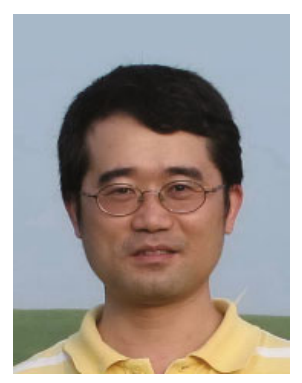

Xueyuan Chen received his BSc from University of Science and Technology of China (1993) and PhD from FJIRSM, CAS (1998). From 2001 to 2005, he was a postdoctoral research associate at the Chemistry Division of Argonne National Laboratory, Department of Energy of USA, where he studied the photophysics and photochemistry of heavy elements. In 2005, he joined the FJIRSM, where he is currently a professor and group leader in material chemistry and physics. His research focuses on the chemistry, optical spectroscopy and bioapplications of lanthanide-doped luminescent nanomaterials.

中文摘要 苂光生物分析技术在科研及医疗机构已获得广泛应用. 常规的苂光免疫分析方法由于采用传统生物探针(如荧光染料及量 子点等)作为标记, 易受到杂散光及生物组织自荧光的干扰. 利用无机稀土纳米苂光探针优异的发光性能, 如长苂光寿命的下转移发 光、近红外激发的上转换发光以及无需激发源的长余辉发光, 可有效解决背景苂光的干扰. 本文从基础的物理化学性能到生物应用角 度出发综述了无机稀土纳米发光材料的最新进展, 包括材料的控制合成、表面功能化、光学性能及其在无背景荧光生物分析方面的 应用示范, 并对该类材料未来的发展趋势与努力的方向作了进一步的远景展望. 